\title{
Using A-Train Observations to Evaluate Cloud Occurrence and Radiative Effects in the Community Atmosphere Model during the Southeast Asia Summer Monsoon
}

\author{
ElizABETH BERRY AND GERALD G. MACE \\ University of Utah, Salt Lake City, Utah \\ ANDREW GETTELMAN \\ National Center for Atmospheric Research, Boulder, Colorado
}

(Manuscript received 15 October 2018, in final form 5 April 2019)

\begin{abstract}
The distribution of clouds and their radiative effects in the Community Atmosphere Model, version 5 (CAM5), are compared to A-Train satellite data in Southeast Asia during the summer monsoon. Cloud radiative kernels are created based on populations of observed and modeled clouds separately in order to compare the sensitivity of the TOA radiation to changes in cloud fraction. There is generally good agreement between the observation- and model-derived cloud radiative kernels for most cloud types, meaning that the clouds in the model are heating and cooling like clouds in nature. Cloud radiative effects are assessed by multiplying the cloud radiative kernel by the cloud fraction histogram. For ice clouds in particular, there is good agreement between the model and observations, with optically thin cirrus producing a moderate warming effect and cirrostratus producing a slight cooling effect, on average. Consistent with observations, the model also shows that the median value of the ice water path (IWP) distribution, rather than the mean, is a more representative measure of the ice clouds that are responsible for heating. In addition, in both observations and the model, it is cirrus clouds with an IWP of $20 \mathrm{~g} \mathrm{~m}^{-2}$ that have the largest warming effect in this region, given their radiative heating and frequency of occurrence.
\end{abstract}

\section{Introduction}

Clouds exert a diverse and significant influence on Earth's radiation budget, and understanding how clouds may change in a warming climate continues to be a major challenge (Stephens 2005; Dufresne and Bony 2008). While the Intergovernmental Panel on Climate Change (IPCC) reported numerous improvements in various aspects of the representation of clouds in their Fifth Assessment Report (AR5), differences in cloud feedbacks are still responsible for much of the variability in estimates of climate sensitivity (Boucher et al. 2013). Generally defined as the change in surface temperature resulting from a doubling of $\mathrm{CO}_{2}$, the climate sensitivity ranges from 2.1 to $4.7 \mathrm{~K}$ (Andrews et al. 2012). A large amount $(70 \%)$ of the variability in climate sensitivity has been attributed to cloud feedbacks (Vial et al. 2013). Therefore, an accurate representation of clouds in general circulation models (GCMs) is a high priority

Corresponding author: Elizabeth Berry, betsy.berry@utah.edu
(Stevens and Bony 2013). Satellite observations will continue to play a crucial role in this effort by advancing our understanding of how clouds interact with their environment (Mace and Berry 2017).

While the cloud radiative effect (also known as the cloud forcing) measures the radiative impact of clouds (i.e., the flux change in a spectral band at some defined vertical boundary over what would occur in clear sky), the cloud feedback measures the change in cloud radiative effect due to a change in surface temperature at equilibrium (Soden et al. 2004; Sherwood et al. 2014). To better understand the source of uncertainty in cloud feedbacks, the role of different cloud types has been investigated (Ceppi et al. 2016; Gettelman and Sherwood 2016). It is well established that much of the spread in predicted cloud feedback in climate models is associated with marine boundary layer (MBL) clouds (Bony and Dufresne 2005; Caldwell et al. 2016). The sign of the MBL cloud feedback is uncertain at this time although most models suggest that MBL cloud cover decreases with warming (Sherwood et al. 2014) implying that the feedback is positive. In 
contrast, models show consensus for a positive high-cloud feedback (Soden and Vecchi 2011; Zelinka et al. 2013). This is consistent with the proportionally higher anvil temperature (PHAT) hypothesis, which predicts a positive longwave feedback as a result of tropical anvil clouds rising in a warmer climate (Zelinka and Hartmann 2010). There is some observational evidence, although not fully convincing at this time, that this change in high clouds may already be occurring (Norris et al. 2016).

A common approach for calculating climate feedbacks is the radiative kernel method (Soden and Held 2006). Using this method, individual climate feedbacks are determined as the product of two parameters, the radiative kernel of the base state (i.e., sensitivity of the radiation to the feedback variable) and a climate response pattern (i.e., the change in the feedback variable, normalized by the surface temperature change between two states). But given that the radiative effects of clouds are highly nonlinear, the traditional radiative kernel method is not suitable. Instead, cloud feedback has been obtained as a residual or estimated from changes in cloud radiative effect, while accounting for cloud masking effects, whereby clear-sky responses are diminished by the presence of clouds (Soden et al. 2008).

A novel technique for directly calculating cloud feedbacks was introduced by Zelinka et al. (2012). In this approach, histograms of cloud radiative kernel and cloud fraction are expressed as a joint function of cloud-top pressure (CTP) and optical thickness $\tau$, with bins representing different cloud types following the ISCCP convention (Rossow and Schiffer 1999). Multiplying the cloud radiative kernel by the change in cloud fraction due to a doubling of $\mathrm{CO}_{2}$, and normalizing by the change in surface temperature, yields the cloud feedback for each CTP $-\tau$ bin. A distinct advantage of this method is the ability to quantify the contribution of specific cloud types to the overall cloud feedbacks. For instance, Zelinka et al. (2012) show that high clouds produce a wider range of shortwave and longwave feedbacks across models than low clouds. Also, high clouds, despite having the largest influence on the longwave cloud feedback, contribute less to the net cloud feedback than low clouds because their longwave (LW) and shortwave (SW) impacts partially cancel. The wide range of SW and LW feedbacks for high clouds among models suggests that more work needs to be done on the validity of high-cloud representation. In addition, the spread in the SW and LW feedback components highlights a discrepancy among models, which should not be overlooked in light of the consensus in highcloud net feedback.

Satellite observations are playing an increasingly important role in evaluating how well clouds are represented in models, in terms of their occurrence, properties, and radiative effects (Klein et al. 2013; Wang and Su 2013; Dolinar et al. 2015). In particular, several studies have identified areas of progress and outstanding issues with the representation of high-level clouds. Tsushima et al. (2013) showed that errors in cloud radiative effects are primarily due to errors in cloud fraction and cited a systematic low bias in the frequency of anvil cirrus in the tropics, with the implication that the positive longwave feedback expected from the PHAT hypothesis could be underestimated in models. Evaluation of cloud vertical structure in models has shown that deep convective clouds do not reach as high in altitude as observed $\mathrm{Su}$ et al. 2013), and that simulated high-level clouds are geometrically too thick (i.e., fill too many upper levels of the column) compared to observations (Cesana and Waliser 2016). In terms of cloud microphysics, the intermodel spread and errors in cloud water content are largest in the upper troposphere (Jiang et al. 2012) and large discrepancies remain in the annual mean cloud ice water path (IWP), ranging from a factor of 2 up to a factor of 10 difference between models and observational datasets when considering the means of the IWP PDF (Li et al. 2012). Lauer and Hamilton (2013) report large differences in cloud amount and liquid water path but relatively good agreement in the simulation of cloud radiative effects compared to satellite observations, suggesting that tuning has been applied to achieve radiative balance. This result makes sense given that the total radiative flux is known quite well, while cloud properties like water path are not constrained as tightly by observations. In their assessment of liquid clouds, Lauer and Hamilton (2013) conclude that there is a critical need for a similar assessment of ice clouds in order to identify model deficiencies that require attention.

Berry and Mace (2014) used A-Train satellite data to perform an analysis of ice-cloud properties and radiative effects over a particular region dominated by the northern summer monsoon in Southeast Asia. Several findings emerged from that paper that motivate this research. Berry and Mace (2014) show that the frequency distribution of ice water path is highly skewed such that the median of the IWP PDF is a much more representative statistic of the radiative effect of tropical ice clouds. In particular, they demonstrated that the mean of the IWP PDF - a measure of central tendency often used in model-observation comparisons (Jiang et al. 2012) is a particularly poor diagnostic of the TOA radiative effect of these clouds because of the skewness of the PDF. Second, Berry and Mace showed that given their frequency and radiative properties, cirrus with an ice water path around $20 \mathrm{~g} \mathrm{~m}^{-2}$ contribute most significantly to the heating at the top of the atmosphere, leading to a conclusion that radiatively important cirrus 
are those that are optically thin and characteristic of the median ice water path.

Here, we seek to determine whether ice clouds simulated in a leading GCM, the Community Atmosphere Model, version 5 (CAM5; Neale et al. 2010), are heating the atmosphere in a manner similar to what has been diagnosed from measurements. Our goal is to ascertain to what extent the simulated ice clouds reproduce radiative effects like those exhibited in the A-Train observations. In particular, is heating in the model upper troposphere distributed similarly with IWP as is diagnosed from measurements? The answer to this question has implications for the well-known positive feedback found to exist in most GCMs where tropical cirrus rise in response to surface warming (Zelinka and Hartmann 2010). We contend that if the upper-tropospheric heating in GCMs is distributed similarly with IWP as is found in nature, then a measure of validity can be ascribed to the model predictions of positive feedback.

To answer these questions, we adapt the radiative kernel framework to A-Train observations and CAM5. While we are unable to examine cloud feedback given the short-term nature of the A-Train satellites, we can evaluate the present-day cloud occurrence and radiative effects. In addition, we create cloud radiative kernels that are derived from averages of observed and simulated clouds, in a fashion similar to Yue et al. (2016), in order to evaluate potential differences in the sensitivity of the TOA radiation to cloud types. Using this methodology, differences in cloud radiative effects between the model and observations can arise from differences in cloud fraction and/or differences in the sensitivity of the TOA radiation to cloud types. While we present results of cloud occurrence and radiative effects for all cloud types, we particularly focus on ice clouds and our understanding of this cloud type.

\section{Data and methodology}

\section{a. Observations}

This study focuses on a 2-yr period (2007-08) in Southeast Asia $\left(5^{\circ} \mathrm{S}-25^{\circ} \mathrm{N}, 80^{\circ}-120^{\circ} \mathrm{E}\right)$ during the summer monsoon (June-September). During this season, the region experiences extremely high cloud-cover amount, in excess of $80 \%$, and is dominated by high-level clouds (Das et al. 2017), making it an ideal location for studying tropical cirrus.

The A-Train constellation of satellites has provided more than a decade of near simultaneous observations of the atmosphere, clouds, and radiation (L'Ecuyer and Jiang 2010). Moreover, the active sensors in the ATrain, CloudSat and CALIPSO (CC), have provided vertically resolved measurements of hydrometeors and aerosols (Stephens et al. 2018). The combination of passive and active sensors in the A-Train provides independent information about clouds that can be used for deriving cloud properties (Mace 2010; Delanoë and Hogan 2010; Henderson et al. 2013).

The synergy of the active remote sensors has been especially useful for understanding cloud vertical structure and retrieving cloud properties. The $94-\mathrm{GHz}$ Cloud Profiling Radar (CPR) on CloudSat provides measurements of radar reflectivity $(Z)$ profiles (Tanelli et al. 2008). CALIOP, the optical lidar on CALIPSO (Winker et al. 2010) provides measurements of attenuated backscatter and depolarization. While the CPR provides information primarily on optically thicker hydrometeor layers, the lidar senses optically thin clouds that are often below the sensitivity of the radar. Taken together, observations from $C C$ provide detailed and unprecedented cloud statistics (Mace et al. 2009; Mace and Wrenn 2013). The lidar is particularly important for describing the full range of tropical ice clouds, given that the lower third of the cloud ice water path PDF is observed by the lidar only, and that both the lidar and radar are necessary to characterize the cirrus that are most important radiatively (Berry and Mace 2014).

In this study we take advantage of the $C C$ measurements to characterize the clouds and radiation in Southeast Asia and to evaluate ice clouds simulated in a general circulation model. Hydrometeor layers in the $C C$ data are identified from the combined radar-lidar cloud mask in the radar-lidar geometrical profile product (RLGEOPROF) CloudSat dataset (Mace and Zhang 2014), and single-layer clouds are identified as profiles with only one cloud layer present. The ice and liquid-cloud properties are obtained separately. Liquid-cloud microphysical properties, including water content and effective radius $r_{e}$ are derived with a $Z-\tau$ or $Z$-LWP retrieval (Mace 2010). Ice-cloud microphysical properties are obtained from a combined $C C$ optimal estimation retrieval in the level $2 \mathrm{C}$ ice cloud property product (2C-ICE) data product (Deng et al. 2015). The 2C-ICE retrieval is combined with the liquid-cloud retrieval, such that clouds are all ice above the freezing level. Thermodynamic profiles of temperature $T$ and relative humidity are obtained from the European Centre for Medium-Range Weather Forecasts Auxiliary (ECMWF-AUX) CloudSat dataset, which interpolates ECMWF state variables to the CPR bins (Partain 2007).

The deep convection associated with the monsoon does present a challenge for $C C$. In heavy precipitation, the radar signal often becomes fully attenuated and is typically complicated by multiple scattering, thereby affecting retrievals that do not account for these effects (Battaglia 
et al. 2007; Haynes et al. 2009). Correcting for multiple scattering in convection is highly uncertain (Matrosov et al. 2008). Furthermore, the presence of supercooled liquid in deep convection produces dense graupel and hail particles, which make the typical assumptions in ice-cloud retrievals invalid (Delanoë and Hogan 2010). Therefore, we focus our discussions on upper-tropospheric ice-phase (hereafter, cirrus) clouds because we are interested in their unique role in the radiation budget and cloud feedbacks, and for which the retrieved microphysics are more certain (Deng et al. 2013).

\section{b. Model}

We examine model output from the National Center for Atmospheric Research (NCAR) CAM5. The model was run globally for 2005-08 in a standard climate configuration using observed sea surface temperatures and observed sea ice fraction. The simulation operated with a horizontal resolution of $1.9^{\circ} \times 2.5^{\circ}, 30$ vertical levels, and a physics time step of $30 \mathrm{~min}$.

Stratiform cloud microphysics are represented by a two-moment scheme that predicts the mixing ratio and number concentration for four hydrometeor species including cloud water, cloud ice, rain, and snow (Morrison and Gettelman 2008). From the shallow (Park and Bretherton 2009) and deep (Zhang and McFarlane 1995) convection schemes, detrained condensate is added to cloud liquid and ice using the detrained mass with an assumed mean volume radius $(8 \mu \mathrm{m}$ for liquid and $32 \mu \mathrm{m}$ for ice) to estimate number (Neale et al. 2010). A simple linear partition between liquid and ice over the range of $-10^{\circ}<T<-40^{\circ} \mathrm{C}$ is used for detrained condensate.

The simulation of ice cloud allows for supersaturation with respect to ice and nucleation by aerosol particles (Gettelman et al. 2010). The ice-cloud fraction is calculated using relative humidity based on total ice water (ice mass plus vapor) mixing ratio. The autoconversion of cloud ice to snow occurs at a threshold diameter of $200 \mu \mathrm{m}$.

The radiation scheme used in CAM5 is the Rapid Radiative Transfer Model for GCMs (RRTMG; Iacono et al. 2008; Mlawer et al. 1997). Aerosols are a prognostic variable and their radiative effects are included in the clear-sky and cloudy calculations. Vertical cloud fraction and precipitation are diagnostic variables.

As an example of the CAM5 data, Fig. 1 shows cloud and atmospheric properties for a particular grid box, which is typical of Southeast Asia. Characteristic of this region, the cloud fraction is high throughout the upper troposphere. The freezing level is located around $5 \mathrm{~km}$, and the cloud microphysics indicate that there is no liquid present above $6 \mathrm{~km}$.

\section{c. Model-observation comparison}

There are a few considerations for making the most direct comparison between the satellite data and model output. First, we analyze the same geographic domain and time of year in the historical run of the model. Second, we try to more closely match the time and horizontal space resolution of the CloudSat data. We examine 3-hourly instantaneous output around the time of the satellite overpass (0130 and 1330 UTC), which is especially important for the diurnal cycle of clouds and shortwave radiative effects. For ice clouds, we include all ice species from the model (cloud ice and snow) for an equivalent comparison with the $C C$ data, which does not distinguish separate ice species (Waliser et al. 2009).

Given that the spatial resolution of CAM5 is quite different from $C C$, with variables representing the average conditions over a comparatively large area, we would not expect the same variability in the model cloud properties compared to $C C$. And since the gridbox cloud properties (vertical cloud fraction, microphysics, and radiation) are the result of a mixture of clouds that are combined together, the radiative fluxes and cloud radiative effects from CAM5 cannot readily be parsed to the contributions from specific cloud types. To account for these differences and make a more consistent comparison with $C C$, we employ a sampling technique to approximate the subgrid statistics in a manner that has become common in model-measurement comparison studies (Jakob and Klein 1999; Collins 2001). For example, using 100 subcolumns and a maximum-random overlap assumption, a gridbox cloud fraction of $40 \%$ at $5 \mathrm{~km}$ would result 40 out of 100 subcolumns containing cloud at that level. The microphysical properties associated with cloudy layers remains the same at a given height across the subcolumns. Doing this for each model layer then yields 100 subcolumns with varying amounts of cloud. For the subcolumns, single-layers are identified using the cloud fraction profile $(0=$ no cloud, 1 = cloud). When only one cloud layer is identified in the vertical, we consider that subcolumn to contain a single-layer cloud. Figure 2 shows the resulting microphysical profiles for 100 subcolumns belonging to the grid box shown in Fig. 1. It can be seen that creating the subcolumns for this grid box results in a cloud scene containing mostly single-layer cirrus, along with a small fraction of deep-layer cloud. The effective radius in Fig. 2 highlights the cloud vertical structure, with the smallest ice crystals at cloud top transitioning to larger ice crystals near cloud the cirrus cloud base, and liquid drops below the freezing level. Next, using these subcolumns of cloud properties and the CAM5 atmospheric profiles of temperature $T$ and 
CAM Clear-sky Net Solar Flux at TOA $=1121$

CAM Clear-sky Net Longwave Flux at TOA $=265$

CAM Net Solar Flux at TOA $=782$

CAM Net Longwave Flux at TOA $=137$
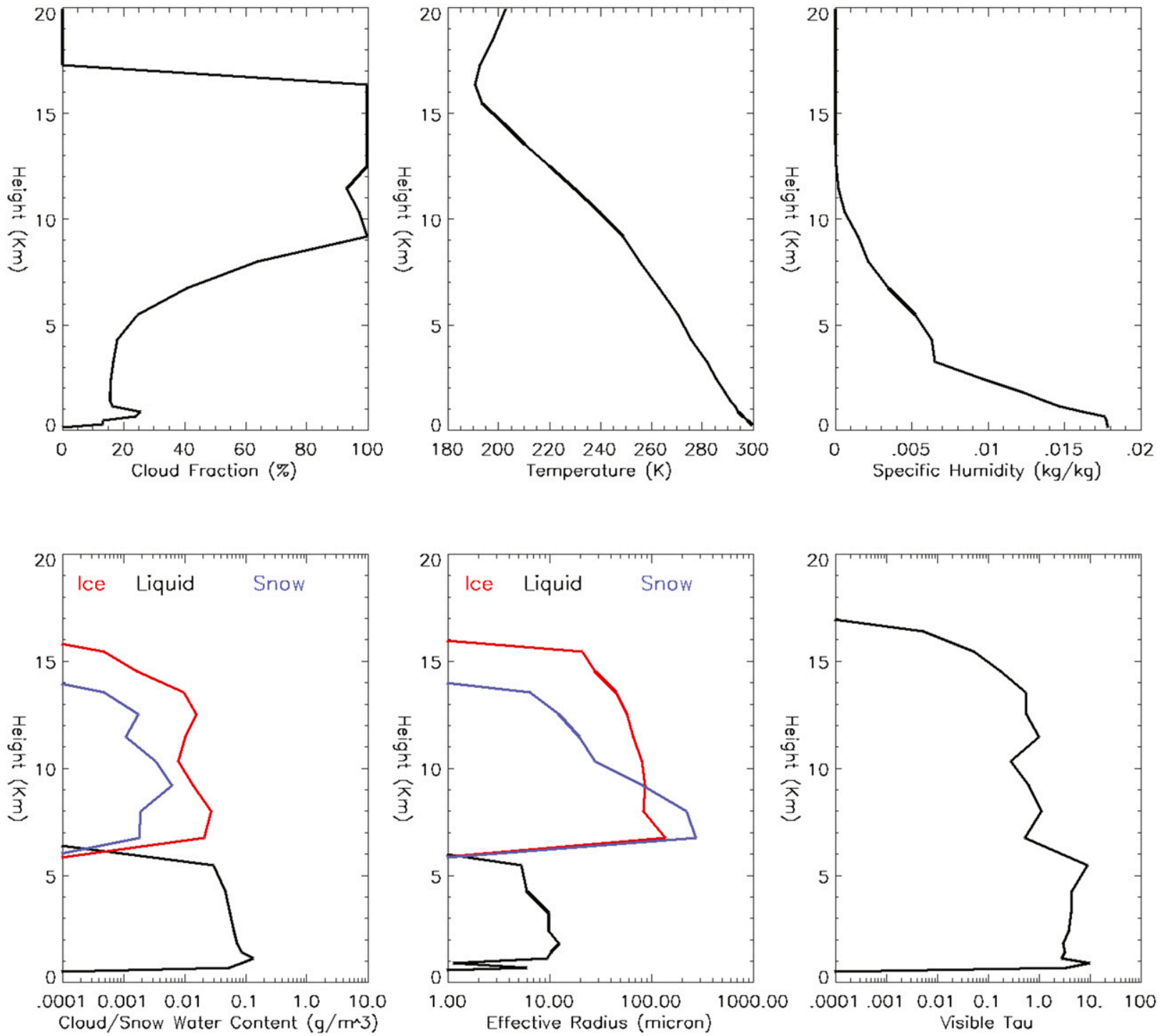

FIG. 1. CAM5 thermodynamics and cloud properties for a given grid box at $16.11^{\circ} \mathrm{N}, 120.0^{\circ} \mathrm{E}$ on $2 \mathrm{Sep} 2007$. (top left to top right) Cloud fraction, temperature and specific humidity. (bottom left to bottom right) Cloud water content, effective radius, and visible extinction. Liquid and ice microphysical properties are shown in black and red lines, respectively. Radiative flux values $\left(\mathrm{W} \mathrm{m}^{-2}\right)$ are noted at top.

humidity $q$, we compute the radiative fluxes separately for each subcolumn.

Another method for comparing model and observed clouds is to use a satellite simulator to simulate the satellite retrieval of modeled clouds. The COSP satellite simulator for $C C$ satellites (e.g., Bodas-Salcedo et al. 2011) is available in CAM5, and performs much of the same subsampling that our cloud generator does, as well as screening clouds by what the satellite might see. To determine if CAM-COSP (CloudSat +CALIPSO simulator) was needed, we compared maps of monthly mean cloud fraction from $C C$, CAM5-Subsampled (100 subcolumns from each grid box), and CAM-COSP (CloudSat+ CALIPSO simulator). We found that the difference in total cloud fraction between CAM5-Subsampled and CAM-COSP (CloudSat +CALIPSO simulator) was only $1 \%$ ( $79 \%$ and $78 \%$, respectively). Since there was little difference between CAM5-Subsampled and CAMCOSP (CloudSat +CALIPSO simulator), and CAMCOSP (CloudSat + CALIPSO simulator) did not match the observations more closely, we concluded that not using COSP (CloudSat + CALIPSO simulator) and 

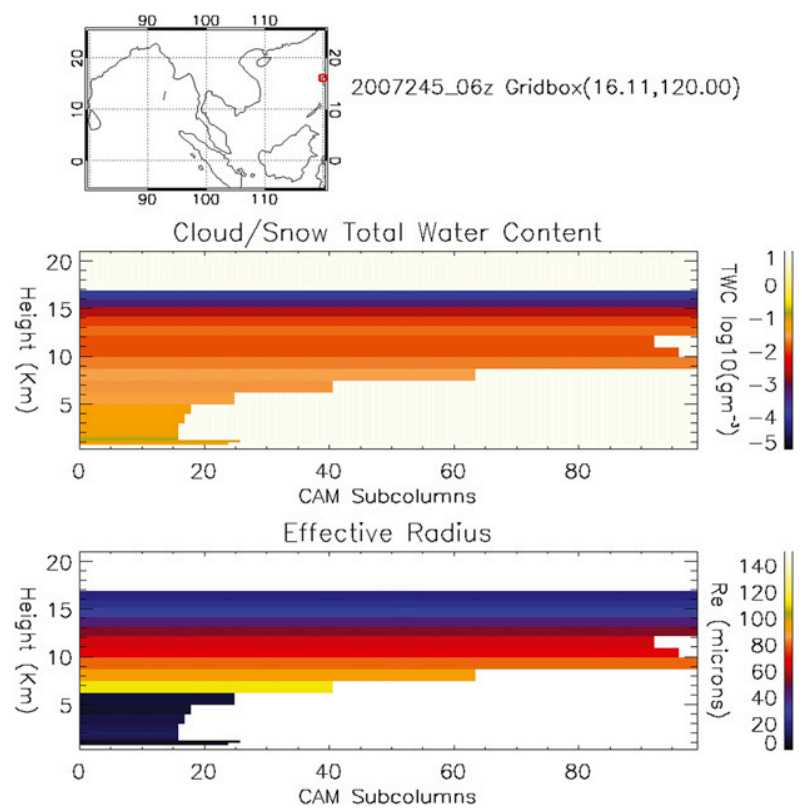

FIG. 2. (middle) Total in-cloud water content and (bottom) effective radius for the 100 CAM subcolumns created from the grid box presented in Fig. 1. (top) The study domain, with the red square highlighting the location of the grid box. Also noted is the date and time for this case study.

applying our subcolumn method was sufficient for approximately the variability of clouds observed by $C C$. It is important to note that while the kernels developed in this study are representative of the instantaneous relationship between the cloud and radiation, our approach of comparing the monthly mean cloud fields to demonstrate that a satellite simulator is not necessary is still valid, given that our results will show that the differences in the mean cloud radiative effects are dominated by the differences in cloud fraction and not the kernels. In addition, we are sampling the model near satellite overpass times to minimize any differences between model and observations due to diurnal-cycle effects.

\section{d. Radiation}

The retrieved and predicted cloud microphysical properties (water content and $r_{e}$ ) from $C C$ and CAM5 are, respectively, used to calculate the cloud radiative properties that then serve as inputs for the radiative transfer model. For CAM5, we include all ice species (ice cloud and precipitating ice or snow) in the calculation of the radiation, which has been shown to be important (Waliser et al. 2011; Li et al. 2014). The ice water content is then the combined contribution from ice cloud and snow. The ice-cloud effective radius and snow radius (diameter/2) are weighted by their respective masses and then averaged to obtain the mean ice effective radius at each model level. We use this ice effective radius to calculate the generalized effective size following $\mathrm{Fu}$ (1996). When the generalized effective size exceeds the maximum size for the parameterization of the ice radiative properties, based on the field data used in $\mathrm{Fu}$ (1996) and Fu et al. (1998), it was set to a maximum value of $120 \mu \mathrm{m}$.

The cloud radiative properties (single-scattering albedo, optical depth, and asymmetry parameter) are determined using parameterizations for liquid cloud (Slingo 1989; Kiehl et al. 1998) and ice cloud (Fu 1996; $\mathrm{Fu}$ et al. 1998). The solar and infrared radiative fluxes are calculated with a two-stream rapid radiative transfer model that uses the $k$-distribution method and correlated- $k$ assumptions (RAPRAD; Toon et al. 1989; Kato et al. 2001; Mlawer et al. 1997). The clear-sky fluxes for each profile/subcolumn are calculated by setting the cloud amount to zero. It is worth noting that obtaining the clear-sky fluxes in this manner can produce a negative bias in the clear-sky longwave flux up to several watts per square meter (Kato et al. 2013). However, we are using the same approach to determine the clear sky for both the observational and model datasets, so the model-observation comparison is not affected. The cloud radiative effect is obtained by differencing the all-sky and clear-sky fluxes. Using this methodology, regional bias errors in cloud radiative effect, when averaged on monthly time scales, are estimated to be 5-10 $\mathrm{W} \mathrm{m}^{-2}$ (Mace 2010).

Figure 3 shows the integrated water path, optical depth, and calculated radiative fluxes for the subcolumns presented in Fig. 2. We find a considerable range in cloud properties and radiative fluxes for the subcolumns within this model grid box. The majority of the subcolumns contain thick cirrus. These cirrus layers tend to have an IWP around $100 \mathrm{~g} \mathrm{~m}^{-2}$ and optical depth near 3 , producing $250 \mathrm{~W} \mathrm{~m}^{-2}$ reflective shortwave and $140 \mathrm{~W} \mathrm{~m}^{-2}$ outgoing longwave radiation. About $15 \%$ of the subcolumns contain deep-layer cloud. By comparison, the deep-layer cloud has a total water path (TWP) around $500 \mathrm{~g} \mathrm{~m}^{-2}$ and optical depth near 70 , resulting in substantial reflected shortwave energy $\left(\sim 750 \mathrm{~W} \mathrm{~m}^{-2}\right)$ and $130 \mathrm{~W} \mathrm{~m}^{-2}$ of outgoing longwave radiation. The mean reflected solar is $359 \mathrm{~W} \mathrm{~m}^{-2}$ and the mean outgoing longwave is $133 \mathrm{~W} \mathrm{~m}^{-2}$ for the 100 subcolumns in this case study. For reference, the CAM output for this case study grid box shows $339 \mathrm{~W} \mathrm{~m}^{-2}$ reflected solar and $128 \mathrm{~W} \mathrm{~m}^{-2}$ outgoing longwave.

A statistical comparison of our calculated radiative fluxes to the CAM5 internally generated radiative fluxes is shown in Fig. 4. We determine the average radiative fluxes for the 100 subcolumns within each grid box (from 

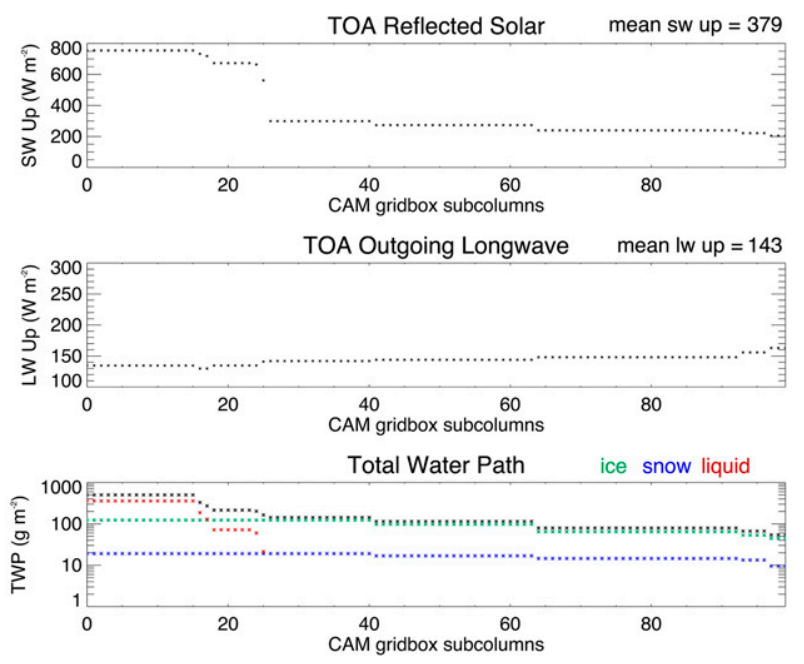

Visible Tau

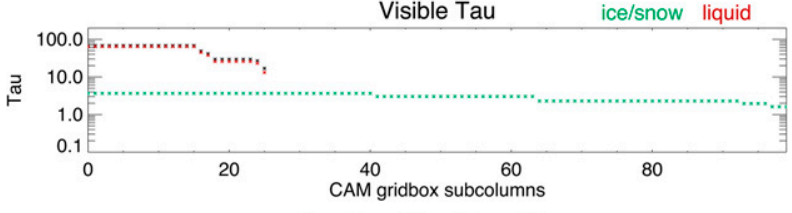

Net Cloud Radiative Effect TOA SFC ATM

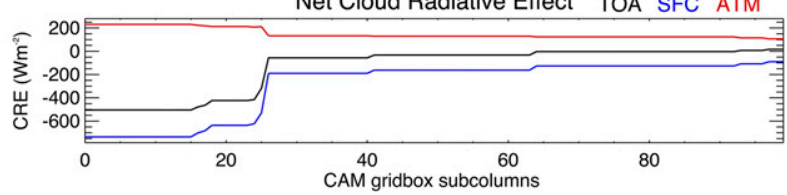

FIG. 3. The radiative fluxes and integrated microphysics for the model subcolumns created from the grid box shown Fig. 1. (top to bottom) Reflected solar at TOA, outgoing longwave at TOA, total in-cloud water path, optical depth, and net cloud radiative effects for the TOA, surface (SFC), and atmosphere (ATM).

RAPRAD) and compare that to the CAM5 gridbox radiative fluxes (from RRTMG). To calculate the radiative fluxes for the model subcolumns, we are using the model values of cloud microphysics (water content and $r_{e}$ ) and atmospheric properties ( $T$ and $q$ ). However, differences in atmospheric constituents, surface properties, and parameterized radiative properties can contribute to differences between the subcolumn calculated mean radiative fluxes and the CAM5 gridbox radiative fluxes. As shown in Fig. 4, we are able to reproduce the mean CAM5 radiative fluxes sufficiently enough to characterize the cloud radiative effects in this region. While there is a fair amount of scatter, indicated by the root-mean-square errors (RMSEs), the biases for the radiative fluxes are nearly negligible. For example, considering the daytime net solar flux at the TOA (Fig. 4c), we find that our calculated radiative fluxes tend to have slightly less reflection overall compared to CAM5 (bias of $3 \mathrm{~W} \mathrm{~m}^{-2}$ ) although the spread at any given point can be much larger. This bias also seems to vary as a function of net solar, where scenes with large net solar $\left(>1000 \mathrm{~W} \mathrm{~m}^{-2}\right)$, typically representative of cirrus, actually show a negative bias. For net cloud radiative effect (Fig. 4g) the agreement is best for scenes with positive radiative effects, owing partly to the lack of solar fluxes at night time. Overall, despite some differences for individual cases, we find good correlation between our calculated radiative fluxes for the model subcolumns, and the CAM5 gridbox radiative fluxes.

\section{e. Creation of cloud radiative kernels}

The cloud radiative kernel $K$, as introduced by Zelinka et al. (2012), gives the sensitivity of the TOA fluxes $R$ to changes in cloud fraction $C$ following

$$
K=\frac{\partial R}{\partial C}
$$

The cloud radiative kernel $\left(\mathrm{W} \mathrm{m}^{-2} \%^{-1}\right)$ is a function of CTP and $\tau$. The model-based cloud radiative kernels created by Zelinka et al. (2012) are derived from synthetic single-layer clouds at each $\mathrm{CTP}-\tau$ bin value and use mean $T$ and humidity profiles averaged from several Coupled Model Intercomparison Project (CMIP; Taylor et al. 2012) models. We set $r_{e}$ at $10 \mu \mathrm{m}$ for liquid and $30 \mu \mathrm{m}$ for ice (cloud top $T<263 \mathrm{~K}$ ). Using a radiative transfer model, the fluxes are calculated with the given cloud properties (CTP, $\tau$, and $r_{e}$ ) at each corner of the cloud-type bin, and then averaged to obtain the TOA flux for that cloud type. The clear-sky fluxes are calculated by removing the cloud, and the cloud radiative effect results from differencing the clear and overcast fluxes. Last, the cloud radiative effect matrix is divided by 100 to yield the change in TOA radiation per change in cloud fraction.

Since the cloud radiative kernel method was introduced, variations on it have followed. Zhou et al. (2013) created a cloud radiative kernel for calculating cloud feedback from observations in the same manner as Zelinka et al. (2012), only substituting ERA-Interim atmospheric variables. Zhou et al. (2014) created a cirrus cloud radiative kernel that allowed for the effective particle diameter to vary as a function of cloud-top temperature. Using CALIPSO observations over a 6 -yr period, they calculated the cirrus cloud feedback. Zhou et al. (2014) found an increase in cirrus cloud amount and altitude, producing an overall positive cirrus cloud feedback.

Yue et al. (2016) created multiple versions of longwave cloud radiative kernels from A-Train satellite observations. An observation-based longwave $K$ was created directly from radiative fluxes measured by Clouds and the Earth's Radiant Energy System (CERES), bypassing the need to calculate radiative fluxes 

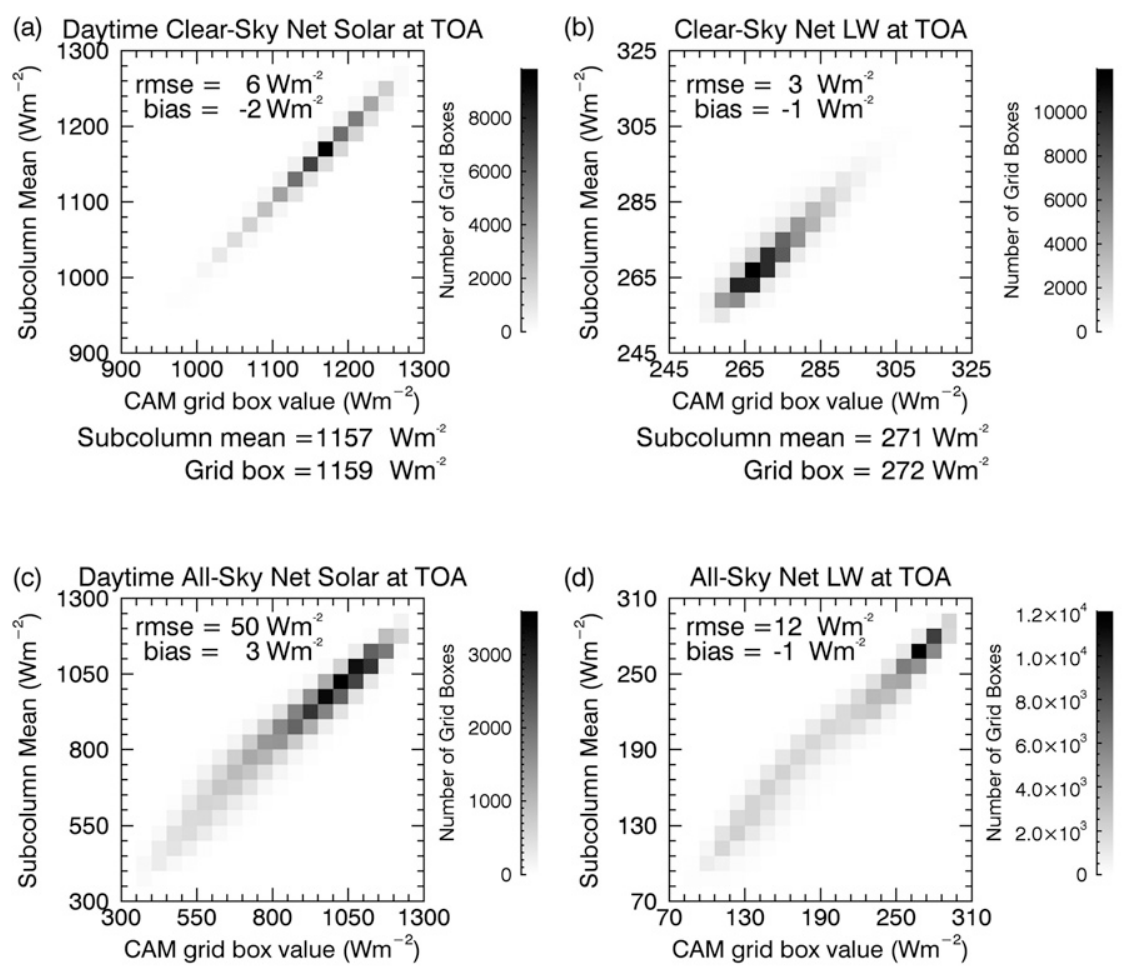

Subcolumn mean $=899 \mathrm{Wm}^{-2}$ Grid box $=896 \mathrm{Wm}^{-2}$

Subcolumn mean $=217 \mathrm{Wm}^{-2}$ Grid box $=217 \mathrm{Wm}^{2}$
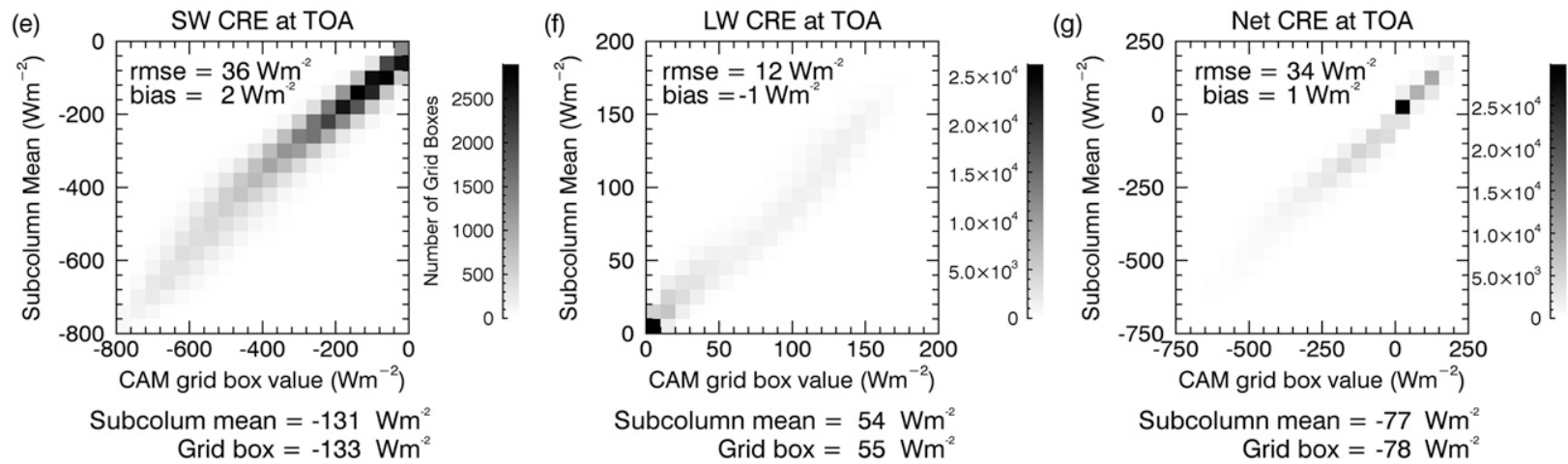

FIG. 4. Comparison of radiative fluxes $\left(\mathrm{W} \mathrm{m}^{-2}\right)$ from CAM5 output and calculated subcolumns for the study domain from June through September 2007 and 2008 (141 032 data points). (a) Clear-sky net shortwave flux at TOA (only daytime values). (b) Clear-sky outgoing longwave radiation at TOA. (c) All-sky net shortwave flux at TOA (only daytime values). (d) All-sky net longwave flux at TOA. (e)-(g) The shortwave (including day and night), longwave, and net cloud radiative effects, respectively. Noted below each panel are the average flux values from the subcolumn means and grid boxes. Bias and root-mean-square error (RMSE) are defined as calculated fluxes minus CAM output.

and assume cloud properties. A calculated longwave $K$ was created using averaged cloud properties $\left(\tau, r_{e}, \mathrm{CTP}\right)$ from the Moderate Resolution Imaging Spectroradiometer (MODIS) instrument and a radiative transfer model. The observed and calculated cloud radiative kernels showed very similar patterns for optically thick and high clouds. However, given that MODIS underestimates the detection of optically thin clouds, the observed $K$ showed a larger TOA radiative sensitivity than their calculated $K$.

In this study, we create observation-based cloud radiative kernels similar to the latter approach of Yue et al. (2016), with cloud properties (water content and $r_{e}$ ) derived from $C C$ and atmospheric properties $(T, q)$ from ECMWF-AUX. In addition, we create a model-specific cloud radiative kernel in a similar manner, with cloud 
properties (water content and $r_{e}$ ) and atmospheric properties $(T, q)$ from CAM5. Then the same radiative transfer scheme is used to obtain the radiative fluxes for the clouds observed by $C C$ and the clouds simulated by CAM5. Similar to Zelinka et al. (2012), our cloud radiative kernels are derived from single-layer clouds. However, the cloud radiative effect in each cloud-type bin is an average cloud radiative effect from many profiles of single-layer clouds with varying cloud properties ( $\tau$ and $r_{e}$ ) within the bin boundaries, as opposed to one prescribed value. The kernels are calculated by dividing the average cloud radiative effect by $100 \%$ cloud cover (cloudy profiles are assumed overcast). Our observationbased and model-specific kernels are derived from their respective atmospheres and cloud properties, but use the same parameterization for radiative properties (Slingo 1989; Kiehl et al. 1998; Fu 1996; Fu et al. 1998) and radiative transfer model (Toon et al. 1989; Kato et al. 2001; Mlawer et al. 1997). Hence, we allow for there to be differences in the sensitivity of the TOA radiation between the observation-based $K$ and model-specific $K$ due to differences in cloud properties but not in the treatment of the radiative properties or the radiative flux calculations.

We use our cloud radiative kernels to calculate the cloud radiative effects in the observations and model, following

$$
R=K C,
$$

where $C$ is the histogram of cloud fraction as a function of cloud-top height $(\mathrm{CTH})$ and $\tau$, and $R$ gives the contribution of each cloud type to the TOA radiation $\left(\mathrm{W} \mathrm{m}^{-2}\right)$. Therefore, $R$ is a function of the cloud radiative kernel and cloud amount. Differences between our observed and modeled cloud radiative effects can arise from differences in the kernel, cloud fraction, or both. The advantage of using the kernel approach is that we can separately evaluate the cloud radiative kernel and cloud fraction for individual cloud types, and quantify how discrepancies in those separate sources of uncertainty lead to differences or agreement (through compensating effects) in cloud radiative effects. In particular, by separately considering the radiative kernel and cloud fraction, we are able to identify compensating errors in the model.

\section{Results}

\section{a. Cloud occurrence}

In Berry and Mace (2014), we examined radar-lidar cloud occurrence statistics in the Southeast Asia region, with some important and relevant findings. The vertical cloud frequency of occurrence is dominated by clouds in the upper troposphere. A classification of cloud layers by base-height and/or geometric thickness indicates distinct maxima for high-level cloud types, with a prevalence of tropical tropopause cirrus and tropospheric cirrus likely associated in some way with convective detrainment. Radar reflectivity values indicate roughly $1 / 3$ of the hydrometeor volumes in the middle troposphere are parts of deeper layers that contain precipitation.

In this study we seek to compare the cloud occurrence statistics from $C C$ observations with CAM5 model output during the summer monsoon (June-September $2007-08)$ in Southeast Asia $\left(5^{\circ} \mathrm{S}-25^{\circ} \mathrm{N}, 80^{\circ}-120^{\circ} \mathrm{E}\right)$. In total, we consider 2.0 million CloudSat profiles, of which just over 940000 (47\%) contain single-layer clouds, $800000(40 \%)$ contain multiple cloud layers (i.e., clear sky separating two or more cloud layers in the vertical) and 260000 (13\%) are clear. For CAM5, our dataset contains 12.0 million subcolumns, of which just over 4.9 million (41\%) contain single-layer clouds, 4.6 million (38\%) contain multiple cloud layers, and 2.5 million $(21 \%)$ are clear. Our sample size for $C C$ is smaller than CAM, because $C C$ provide a curtain of data, while the model provides output for the whole domain at the overpass times of approximately 0130 and 1330 UTC.

The cloud fraction $(C)$ histograms for single-layer clouds in the observations and model are compared in Fig. 5 and summarized in Table 1 . We find relatively good agreement in the overall single-layer cloud fraction, with single-layer clouds accounting for $47 \%$ of all the profiles in the observations and $41 \%$ of all subcolumns from the model. In terms of cloud-top height, the single-layer cloud fraction is dominated by hightopped clouds in both the model and observations. In terms of optical depth, optically thin layers occur most frequently, while optically thick layers occur least frequently in both the models and observations.

The decomposition of single-layer cloud fraction by cloud type (Fig. 5) highlights some differences between the observations and model. The largest differences in cloud type occur for low clouds, and clouds with moderate optical depths (Table 1). The details reveal that the model produces fewer single-layer low clouds (5\%) compared to that observed by $C C(9 \%)$. Evidence of these differences can be seen by examining the individual cloud types. In terms of optical depth, the model produces a greater fraction of single-layer cirrus $(18 \%)$ and smaller fraction of cirrostratus (6\%), compared to $C C$, which observes a cirrus cloud fraction of $15 \%$ and a cirrostratus cloud fraction of $9 \%$. $C C$ also observes more than double the amount of single-layer stratocumulus (6\%) compared to CAM5 (3\%).

Considering all cloudy profiles (single and multiple cloud layers), $C C$ observe a total cloud fraction of $87 \%$ 


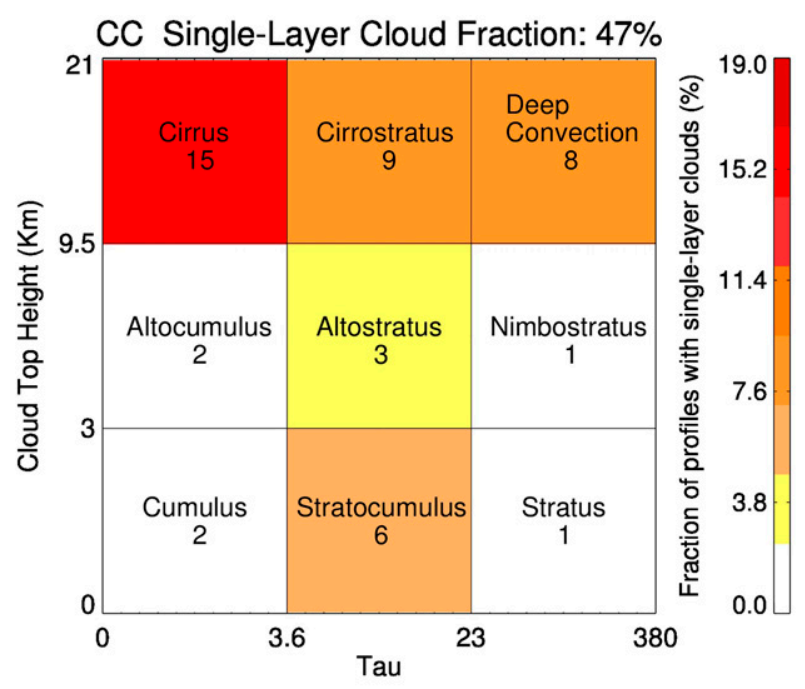

CAM Single-Layer Cloud Fraction: $41 \%$

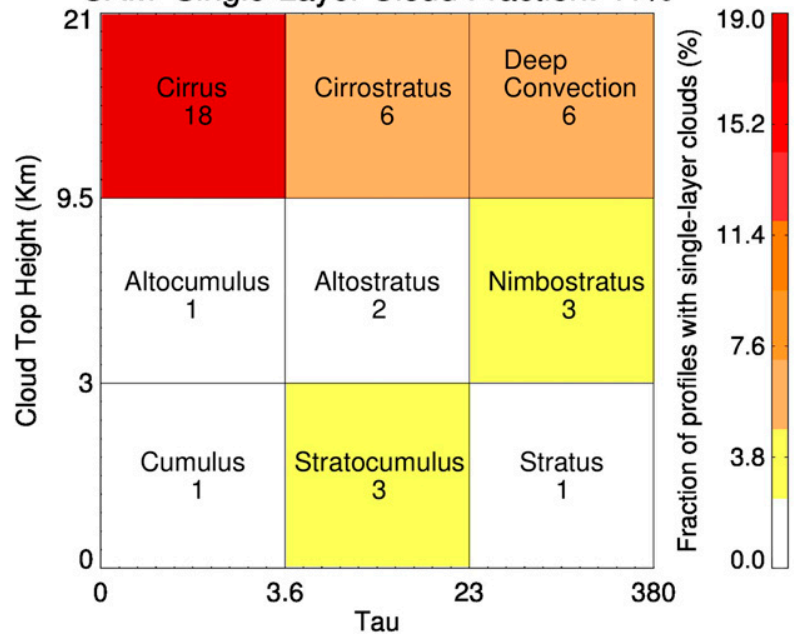

FIG. 5. Fraction of single-cloud layers. The fraction (\%) of each $\mathrm{CTH}-\tau$ cloud type is noted in the bins.

in the Southeast Asia region $\left(5^{\circ} \mathrm{S}-25^{\circ} \mathrm{N}, 80^{\circ}-120^{\circ} \mathrm{E}\right)$, which agrees well with previous seasonal estimates for this region (Mace et al. 2007; Hong and Liu 2015). Multiple cloud layers are present in $40 \%$ of all $C C$ profiles. The total cloud fraction in CAM5 is quite a bit lower, at $79 \%$, with $38 \%$ of all subcolumns containing multiple cloud layers. Too few low clouds in CAM may partially explain the difference in total cloud fraction, given that CAM has less single-layer low cloud than $C C$.

A cloud-type analysis of all cloud layers (single and multiple cloud layers) in the region is shown in Fig. 6 and summarized in Table 2. Relative to all cloud layers, $C C$ observe a greater fraction of middle-cloud layers (31\%), compared to the model $(27 \%)$. For high clouds, the model observes much more ( $>3$ times) cirrus than cirrostratus, especially compared to $C C$. A plausible
TABLE 1. Occurrence frequencies (\%) for single-layer clouds in observations and the model, following $\mathrm{CTH}-\tau$ cloud-type definitions.

\begin{tabular}{lcc}
\hline Cloud type & CloudSat/CALIPSO & CAM5 \\
\hline High & 32 & 30 \\
Middle & 6 & 6 \\
Low & 9 & 5 \\
Thin & 19 & 20 \\
Intermediate & 18 & 11 \\
Thick & 10 & 10 \\
\hline
\end{tabular}

explanation for this apparent shift in high-cloud type may be differences in cloud microphysics (e.g., larger particles in the model), which may be investigated in a future paper. In terms of optical depth, $C C$ observe a
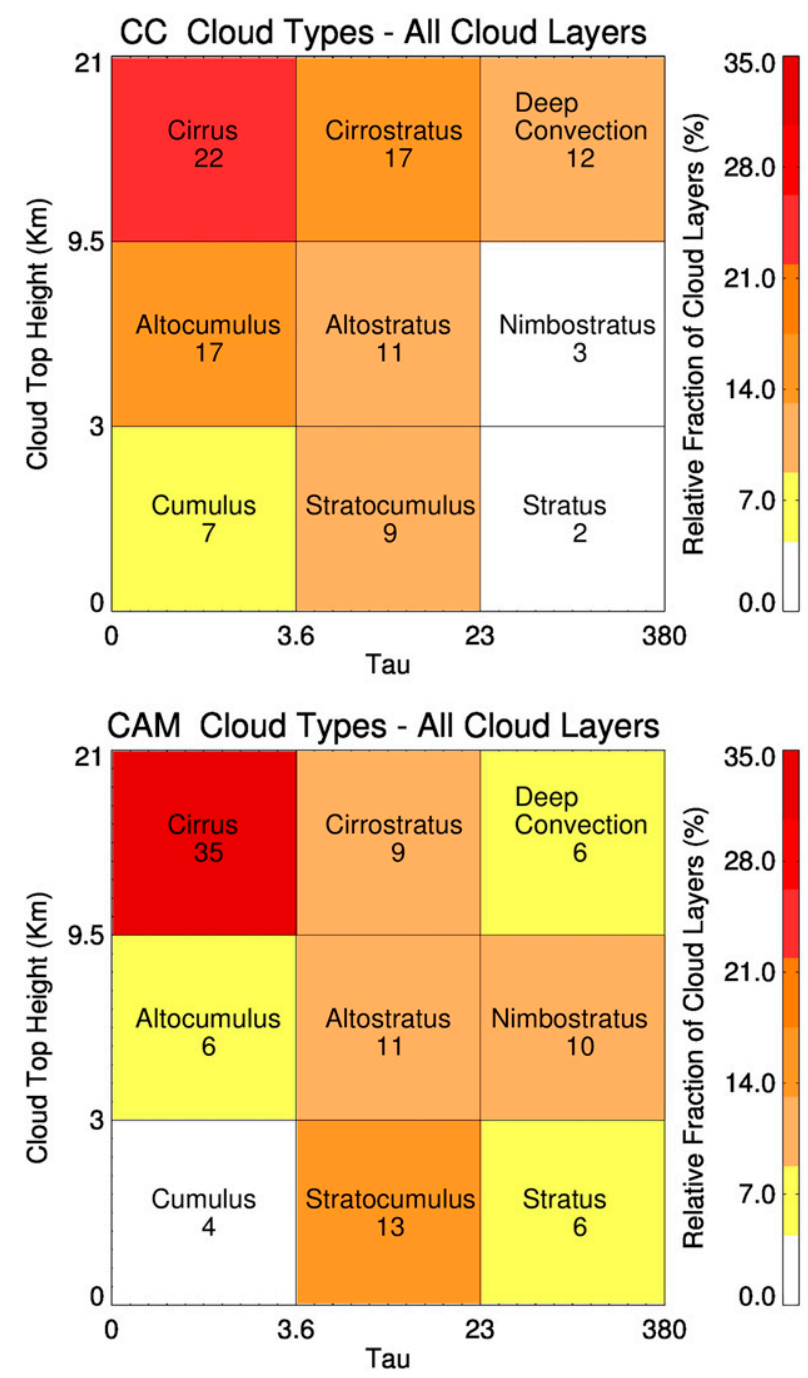

FIG. 6. Distribution of all cloud layers (including single and multiple cloud layers). The relative fraction (\%) of each CTH $-\tau$ cloud type is noted in the bins. 
TABLE 2. Relative frequencies (\%) of cloud types from all cloud layers in observations and the model, following CTH- $\tau$ cloud-type definitions.

\begin{tabular}{lcc}
\hline Cloud type & CloudSat/CALIPSO & CAM5 \\
\hline High & 51 & 50 \\
Middle & 31 & 27 \\
Low & 18 & 23 \\
Thin & 46 & 45 \\
Intermediate & 37 & 33 \\
Thick & 17 & 22 \\
\hline
\end{tabular}

smaller fraction of optically thick clouds (17\%) compared to CAM (22\%). Note there are very few satellite observations of optically thick, lower-topped cloud layers in this region-what would normally be classified as nimbostratus and stratus in the ISCCP parlance.

\section{b. Cloud radiative kernels}

The cloud radiative kernels show the sensitivity of the TOA radiation to changes in cloud fraction. Qualitatively, the kernels represent cloud radiative processes. For example, the TOA longwave kernel is entirely positive, in dicative of column warming resulting from the reduced longwave emission from columns with cloud tops of lower temperature than what would be realized by cloud-free columns. The TOA shortwave kernel is entirely negative, indicative of the reflection of shortwave radiation by all clouds relative to a lower albedo surface. The result of these competing longwave and shortwave effects is shown in the TOA net radiative kernel.

In this study we create observation- and modelderived cloud radiative kernels, which are calculated from data of each single-layer cloud type as described above. In this sense, the radiative effects are an average over the varying range of clouds that occur in a given cloud-type bin, instead of one prescribed cloud as in Zelinka et al. (2012) and Zhou et al. (2013). Quantitatively, in our implementation, the magnitude of the radiative kernels depends on the cloud statistics (macrophysics, microphysics, temporal characteristics) within a given cloud type.

The $\mathrm{LW}, \mathrm{SW}$, and net cloud radiative kernels for $C C$ and CAM5 are presented in Fig. 7. Overall, there is very good agreement for the LW cloud radiative kernel, which shows warming effects increasing with cloud-top height and optical depth, from $0.03 \mathrm{~W} \mathrm{~m}^{-2} \%^{-1}$ for the lowest and thinnest cloud up to $\sim 1.4 \mathrm{~W} \mathrm{~m}^{-2} \%^{-1}$ for the highest and most optically thickest cloud. This spread in the LW cloud radiative kernels across cloud types falls within the observed range of the LW cloud radiative kernels in Yue et al. (2016, their Fig. 6). The largest difference in the LW cloud radiative kernel occurs for altocumulus, with the observations showing a stronger warming effect, indicative of higher cloud tops within this cloud-type bin.

The SW cloud radiative kernels in Fig. 7 show cooling effects increasing with optical depth, with the exception of observed stratus, which is discussed further below. For optically thin clouds $(\tau<3.6)$, the shortwave cooling ranges from -0.2 to $-0.6 \mathrm{~W} \mathrm{~m}^{-2} \%^{-1}$ and the observations and model show good agreement. The largest differences in the SW cloud radiative kernel occur for optically thick clouds $(\tau>23)$, with the model showing more cooling compared to the observations. Overall, the magnitude of the shortwave cooling tends to be a bit larger compared to the global and annual mean SW cloud radiative kernel presented in Zelinka et al. (2012, their Fig. 1b), given that we are focused only on the tropical summer. In addition, for any specific cloud type we may expect some differences compared to Zelinka et al. (2012), given our differences in our kernel methodology. For example, the deep convection in our $C C$ and CAM5 results may have stronger cooling simply because the population of clouds is weighted more toward larger optical depths within the cloud-type bin, compared to the averaged synthetic clouds used in Zelinka et al. (2012).

The cloud radiative kernels represent the average cloud radiative effects from the distributions of clouds within the cloud-type bins. Figures 8 and 9 show these PDFs of TOA net cloud radiative effects (CRE) within each single-layer cloud-type bin, with daytime and nighttime effects separated. The PDFs in Figs. 8 and 9 show the wide range of CRE within each cloud-type bin, which are averaged and divided by $100 \%$ to obtain the TOA net cloud radiative kernels shown in Fig. 7. In addition, given the twice daily ( $\sim 0130$ and 1300 UTC) samples in our dataset, a diurnal variation of cloud fraction for a particular cloud type will impact the cloud radiative kernel. For instance, the largest discrepancies between the model and observations in the cloud radiative kernels (Fig. 7) are for stratus clouds, with $C C$ showing a very modest cooling compared to CAM5. However, we find that this is explained by a diurnal difference in the stratus cloud fraction, with nearly all (93\%) of the $C C$-observed stratus occurring during the nighttime overpass. This is similarly true for deep convection and nimbostratus clouds, in terms of $C C$ observing a higher fraction at night, leading to a warmer mean net CRE, compared to CAM5. It is interesting that CAM5 observes a higher fraction of daytime optically thick clouds, compared to $C C$. Typically the diurnal cycle of monsoon rain peaks in the late afternoon/ early evening over land. We have examined the CAM5 diurnal cycle of precipitation using data from the 

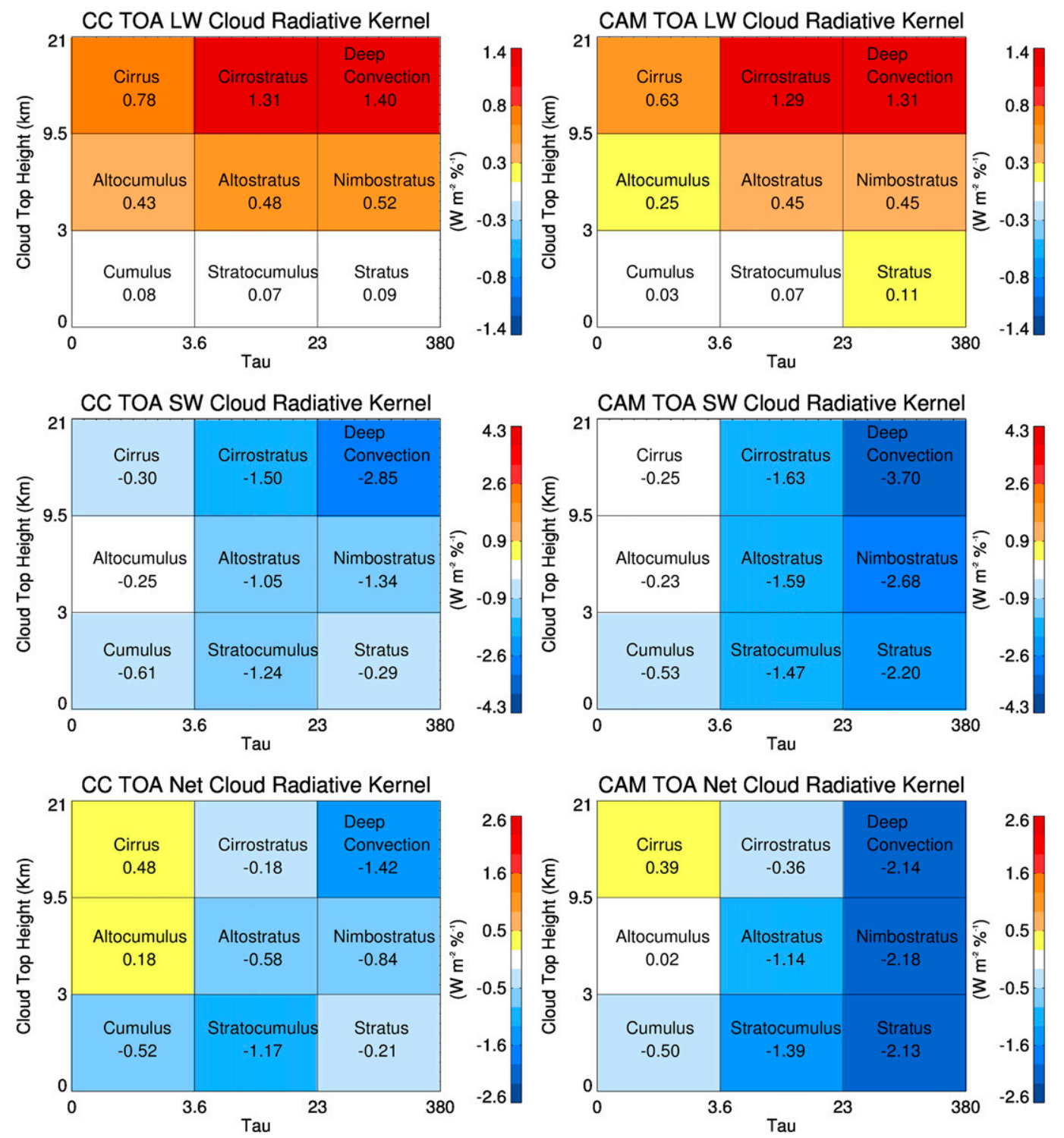

FIG. 7. (top) Longwave, (middle) shortwave, and (bottom) net cloud radiative kernels (based on single-layer clouds) for (left) $C C$ and (right) CAM. The mean cloud radiative kernel value $\left(\mathrm{W} \mathrm{m}^{-2} \%^{-1}\right)$ is noted in each cloudtype bin. Assuming overcast skies, multiply the mean kernel value by $100 \%$ to obtain the cloud-type cloud radiative effect $\left(\mathrm{W} \mathrm{m}^{-2}\right)$.

Tropical Rainfall Measuring Mission satellite, and do find that it peaks a couple hours earlier than the observations over land in the monsoon region. It is plausible that an earlier peak in the diurnal monsoon cycle in the model is causing more optically thick clouds to be present near the 1330 UTC overpass time. However, if we compare the daytime-only mean values, we find much better agreement between the observations and model for the optically thick clouds than suggested by the cloud radiative kernel because of differences in the occurrence of cloud types. In fact, for both CAM5 and the $C C$ observations, deep convection, nimbostratus, and stratus have a daytime median CRE of $-500 \mathrm{~W} \mathrm{~m}^{-2}$.

Using the daytime mean and nighttime mean CRE values (as in Figs. 8 and 9), we can create cloud radiative kernels that assume that each single-layer cloud type is equally likely to occur at the daytime overpass as it is at the nighttime overpass (not shown), instead of the actual day/night fractions in the observations and model. When we remove the effects of the diurnal variations in cloud fraction in this way, we find more agreement between $C C$ and CAM5 and more agreement with the cloud radiative 

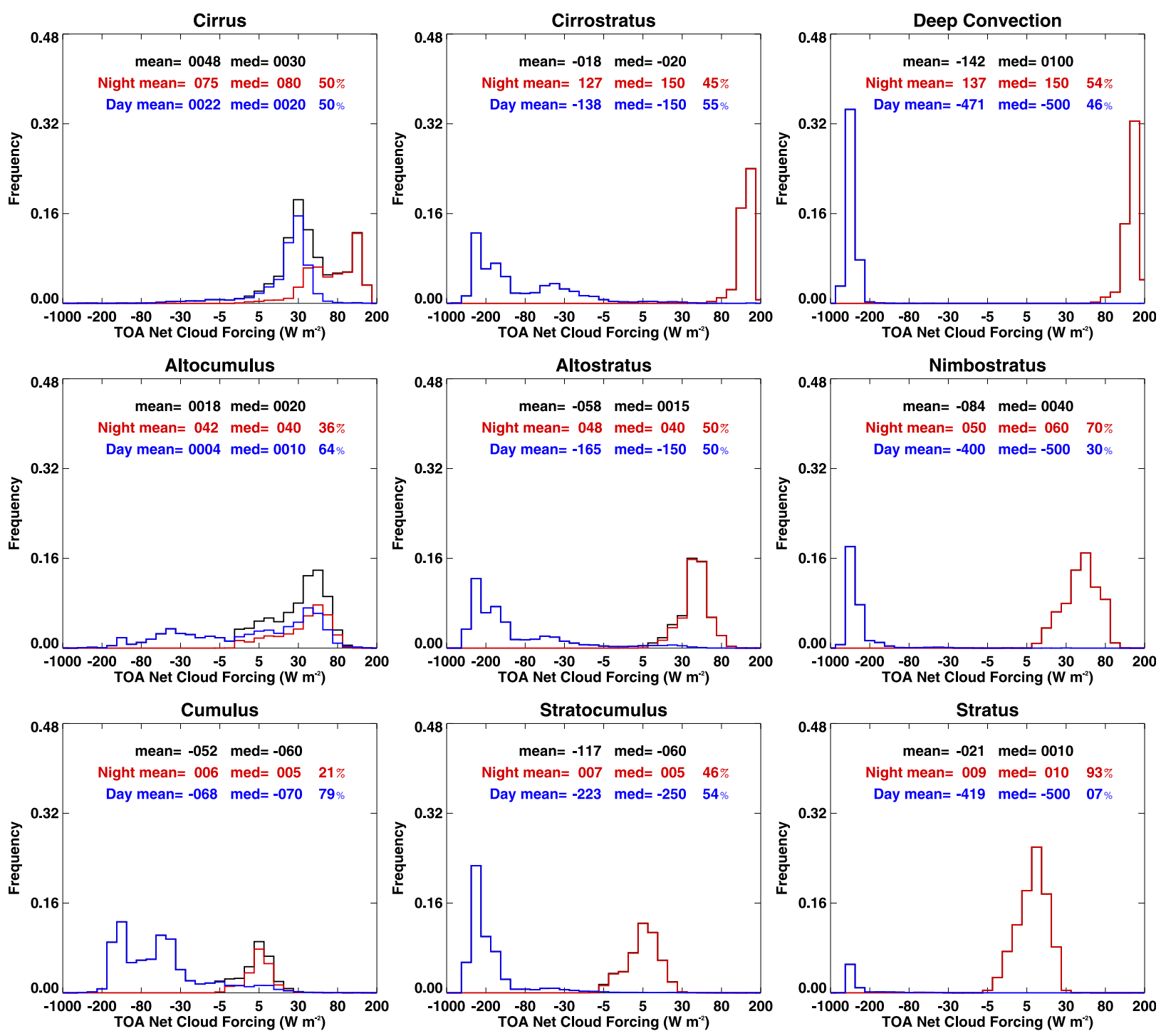

FIG. 8. The distribution of TOA net cloud radiative effect within each single-layer cloud-type bin for $C C$ (black), the daytime-only cloud radiative effect (blue), and the nighttime-only cloud radiative effects (red). The mean and median CRE values are noted for each curve, along with the relative frequency of day and night values.

kernels presented in Zelinka et al. (2012). Hence, some of the differences in the observation-based and modelbased kernels (Fig. 7) are attributed to differences in the day-to-night ratio of clouds, and not attributed to actual differences in the radiative effects of daytime and nighttime clouds. Assuming an equal day and night cloud fraction leads to a more consistent shortwave cooling across cloud-top-height bins within a given $\tau$ bin and shows that the strongest net cooling occurs for the most optically thick and low clouds like Zelinka et al. (2012).

For the low-cloud types cumulus and stratocumulus, the daytime PDFs of CRE (Fig. 9) show that CAM5 tends to have a stronger cooling effect, compared to $C C$ (Fig. 8). In addition, CAM5 has a smaller fraction of single-layer low clouds, as shown in Table 1. Taken together, our findings here show some evidence of the "too few (Table 1), too bright (Figs. 7-9)" tropical lowcloud bias in models (Nam et al. 2012).

For ice clouds, we find quite good agreement in the net cloud radiative kernel between CAM5 and CC observations. In both the model and observations, cirrus produce an overall warming effect between 0.39 and $0.48 \mathrm{~W} \mathrm{~m}^{-2} \%^{-1}$. Although if we look at the individual longwave and shortwave components, we find larger differences that have partially offset each other to give a similar result in the net. 

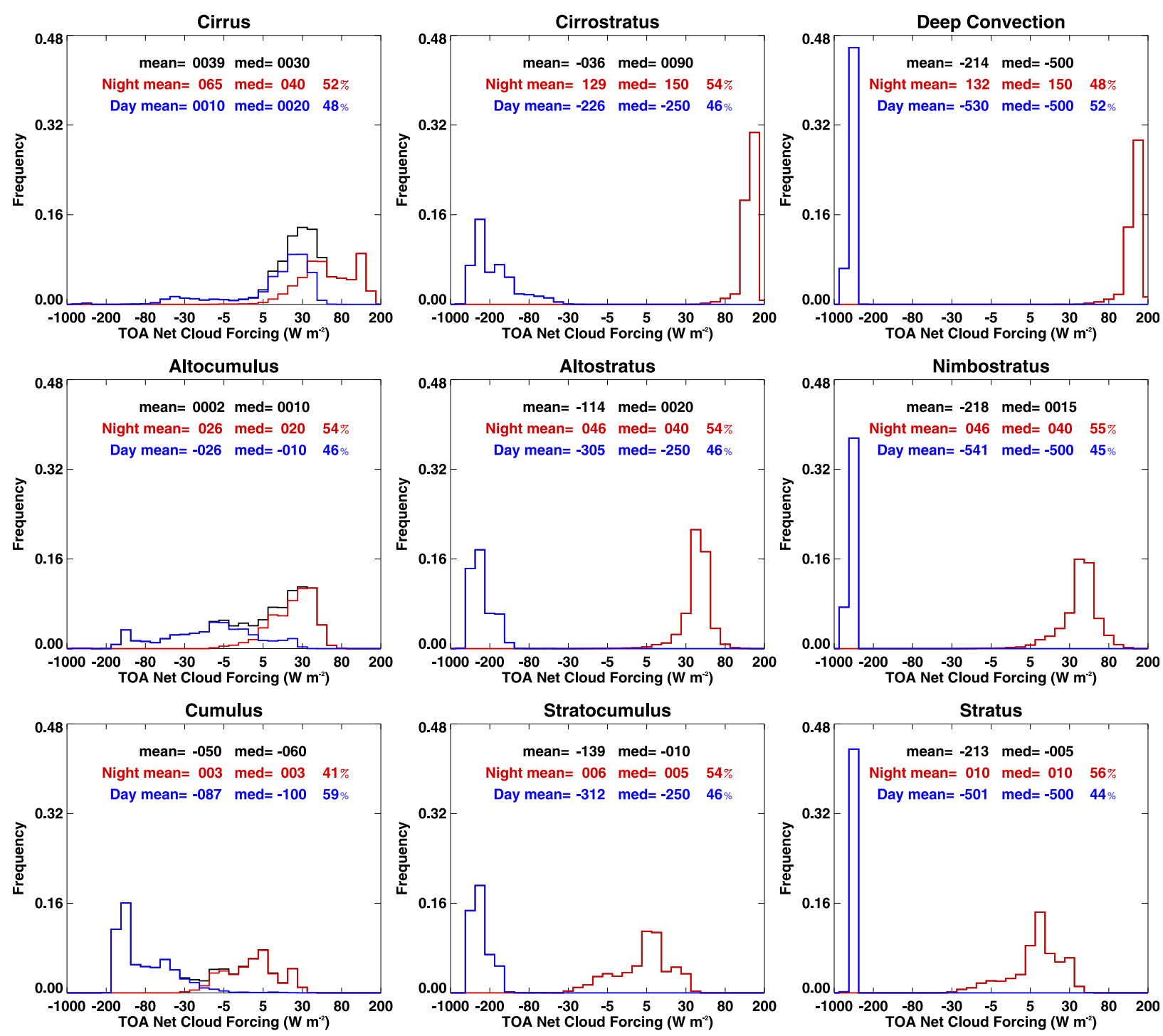

FIG. 9. The distribution of TOA net cloud radiative effects within each single-layer cloud-type bin for CAM5 (black), the daytime-only cloud radiative effects (blue), and the nighttime-only cloud radiative effects (red). The mean and median CRE values are noted for each curve, along with the relative frequency of day and night values.

The cirrus in the model tend to have a weaker longwave and shortwave effect compared to the $C C$ observations. For cirrostratus $(3.6<\tau<23)$, the solar cooling becomes larger than the longwave warming, resulting in a net cooling in the observations and model. This transition from net warming with cirrus $(\tau<3.6)$ to net cooling with cirrostratus is in good agreement with Hong and Liu (2016), who found that the crossover from positive to negative CRE for ice clouds occurs at an optical depth of 4.6.

Overall, the CAM5 net cloud radiative kernel shows relatively good agreement with $C C$ for high and low clouds with optical depths less than 23 (cirrus, cirrostratus, cumulus and stratocumulus). The middle clouds (altocumulus, altostratus, and nimbostratus) show large differences, which is likely related to the small sample sizes of these cloud types. The optically thick clouds also show large differences, owing in part to the wide range of clouds that can exist in that cloud-type bin $(23<\tau<$ $380)$. Overall, the good agreement for the most commonly occurring high (cirrus and cirrostratus) and low (cumulus and stratocumulus) cloud types tells us that the model is making clouds that are reasonably characteristic of the real atmosphere.

\section{c. Cloud radiative effects for single-layer clouds using the kernel technique}

Multiplying the cloud occurrence matrix by the radiative kernel matrix $(\mathbf{C} \times \mathbf{K})$ gives the cloud radiative 

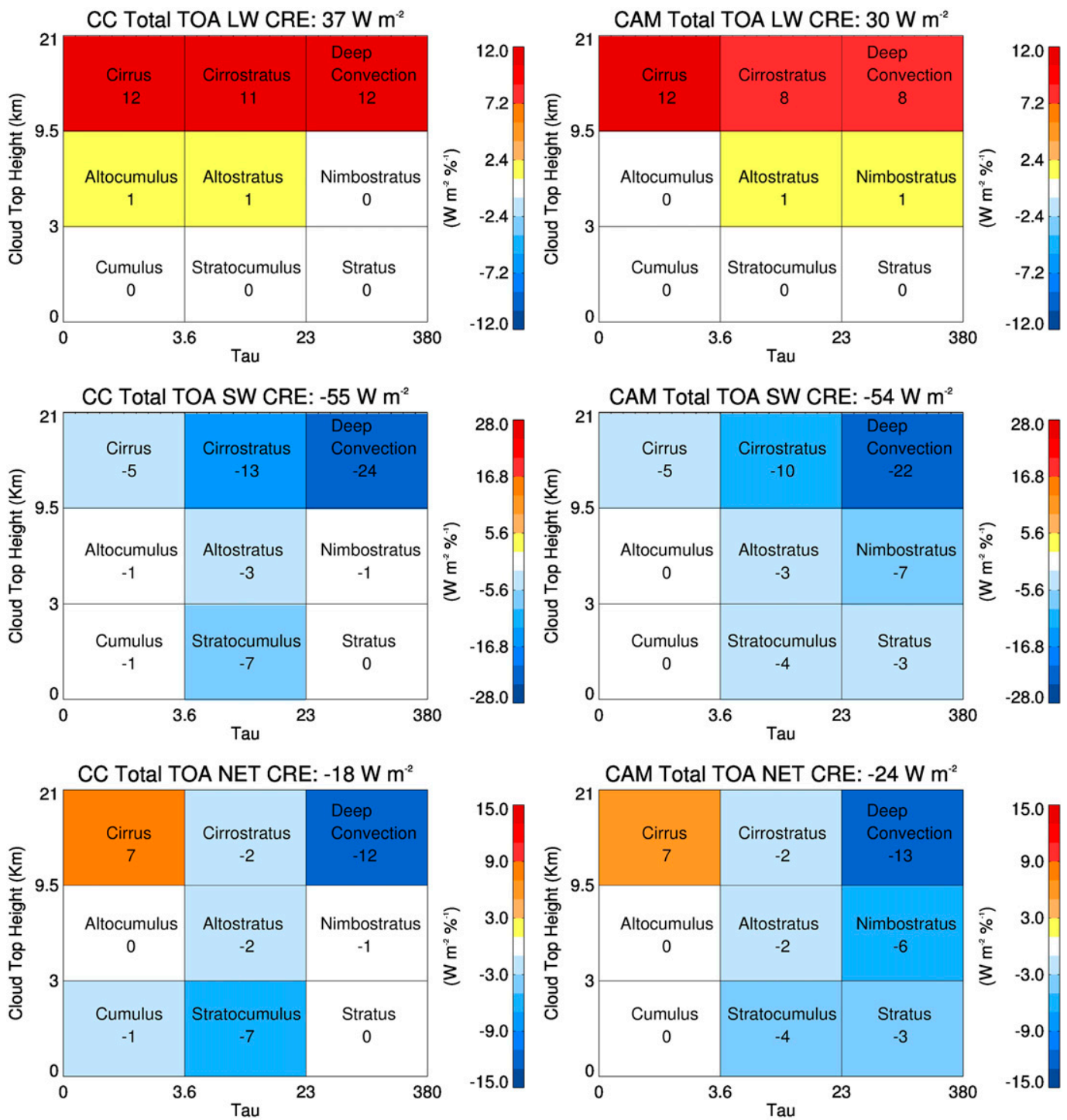

FIG. 10. (top) Longwave, (middle) shortwave, and (bottom) net radiative effect of single-layer clouds [the product of $\mathbf{C}$ (Fig. 5) and $\mathbf{K}$ (Fig. 7)]. The contribution of individual cloud types ( $\mathrm{W} \mathrm{m}^{-2}$ ) to the total CRE for singlelayer clouds is noted in each bin. The sum of the bin values is noted in the title of each panel.

effects for the single-layer clouds layers in this region. Hence the resulting cloud radiative effect depends on both the amount of cloud and the sensitivity of the radiation to the clouds. Therefore, agreement or differences between the model and observed cloud radiative effects can be due to differences in the cloud radiative kernels and/or differences in cloud fraction.

The LW, SW, and net CRE for single-layer clouds is shown in Fig. 10. For the LW CRE, we find more warming for clouds observed by $C C\left(37 \mathrm{~W} \mathrm{~m}^{-2}\right.$ overall) compared to clouds produced by CAM $5\left(30 \mathrm{Wm}^{-2}\right.$ overall). This difference is linked to cirrostratus and deep convection, which occur less frequently in CAM5 and with a slightly smaller longwave sensitivity compared to CC. A consensus exists for the cirrus LW CRE despite some differences, mainly because the higher fraction of cirrus in the model is tempered by a weaker longwave sensitivity.

For the shortwave CRE, we find good agreement overall, with the model and $C C$ demonstrating a total cooling from -54 to $-55 \mathrm{~W} \mathrm{~m}^{-2}$. The largest difference is for nimbostratus, which produces a much larger cooling effect in the model. For nimbostratus, the difference in SW CRE is both due to a difference in cloud fraction, given this cloud type is infrequently unobserved by $C C$, and due to a difference in $\mathrm{SW}$ cloud 
radiative kernel, with the model having a stronger shortwave sensitivity to this cloud type. Stratocumulus, however, exert a stronger cooling in the observations $\left(-7 \mathrm{~W} \mathrm{~m}^{-2}\right)$ compared to CAM5 $\left(-4 \mathrm{~W} \mathrm{~m}^{-2}\right)$, owing to the larger (2 times) fraction of this cloud type in the $C C$ observations.

Overall, we find cooling for the TOA net CRE, with $-18 \mathrm{~W} \mathrm{~m}^{-2}$ from the observations and $-24 \mathrm{~W} \mathrm{~m}^{-2}$ from the model. Much of this difference is primarily explained by nimbostratus cloud, which exhibits significant differences in diurnal cloud fraction and SW cooling. While for the optically thin and intermediate cloud types, we generally find good agreement in net CRE for the observations and model.

In particular, the net CRE for cirrus cloud types shows good similarity for the model and observations. It is cirrus (with the highest top and smallest optical depth) that produce the greatest warming in both the $C C$ observations and CAM5. In addition, the model and observations agree on the magnitude of this warming, with single-layer cirrus producing a net warming of $7 \mathrm{~W} \mathrm{~m}^{-2}$. Cirrostratus clouds, with a larger optical depth, have a near neutral radiative effect in both the observations and model, given that their SW and LW CRE are of similar magnitude. These results are similar to Hong and Liu (2016), who also found a near-zero net effect for ice clouds with $3<\tau<20$, along with a global net ice-cloud CRE of $4 \mathrm{~W} \mathrm{~m}^{-2}$. Such good agreement between the observations and model for these ice-only cloud layers in this region during the summer monsoon is especially noteworthy.

\section{Discussion}

Zelinka and Hartmann (2010) describe a logical response of high clouds to a warming climate (PHAT hypothesis), and GCMs show consensus for a positive LW high-cloud feedback that is consistent with theory (Soden and Vecchi 2011). What has not been known is the degree to which the ice clouds (properties and radiative heating) in models replicate what is found in nature. Our goal in this study has been to apply the active remote sensing of $C C$ to address this issue.

Are simulated ice clouds heating the atmosphere in a manner similar to what is observed in the real atmosphere? We have answered this question in the affirmative (at least for the Southeast Asia summer monsoon region) with observation-based and model-specific cloud radiative kernels. In both the observations and model, we find that it is the optically thin $(\tau<3.6)$ ice clouds that are responsible for heating. Additionally, we find that the net heating for this cloud type for a change in cloud fraction is of similar magnitude between the model and observations, $\sim 0.4-0.5 \mathrm{~W} \mathrm{~m}^{-2} \%^{-1}$. For ice clouds with $\tau>3.6$, the solar effects become larger than the LW effects, producing a similar net cooling in both the $C C$ observations and CAM5.

To what extent do simulated clouds reproduce radiative effects like those exhibited in the $C C$ observations? The answer to this question depends on both the sensitivity of the TOA fluxes to changes in cloud fraction (aka, the cloud radiative kernel $K$ ) and the existing cloud amount $C$. We find that the LW CREs produced by CAM5 are very similar to the observations for all single-layer cloud types. In the SW, there is generally good agreement in CRE for the optically thin and intermediate clouds, while the optically thick clouds in CAM5 have a stronger cooling effect than the observations. In the net CRE there is remarkably good agreement for the cirrus cloud types, with the optically thin cirrus producing an overall warming effect of $7 \mathrm{~W} \mathrm{~m}^{-2}$ and cirrostratus $(3.6<\tau<23)$ producing an overall weak cooling effect of $-2 \mathrm{~W} \mathrm{~m}^{-2}$ in the observations and CAM5.

Figure 11 shows single-layer cirrus (cirrus and cirrostratus) cloud properties and calculated radiative effects as a function of IWP for the model subcolumns and observations. Versions of the observational figures are also shown in Berry and Mace (2014), and these, in turn, were motivated by findings reported in Ackerman et al. (1988, their Fig. 13). We find strong similarities in the distributions of IWP for single-layer cirrus clouds in the observations and model. The distributions of the IWP are highly skewed, with a mean IWP $\sim 115 \mathrm{~g} \mathrm{~m}^{-2}$ and a median value of $40 \mathrm{~g} \mathrm{~m}^{-2}$. Examining the $\mathrm{LW}, \mathrm{SW}$ and net TOA CRE as a function of IWP, we see generally similar behavior between the observations and model, with the crossover from net positive CRE to net negative CRE occurring at an IWP of $150 \mathrm{~g} \mathrm{~m}^{-2}$ in both datasets. Weighing the TOA net CRE for each IWP bin by the frequency of occurrence of a given IWP, we find that single-layer cirrus layers contribute a net warming of $\sim 5 \mathrm{~W} \mathrm{~m}^{-2}$ to the total TOA net CRE and that cirrus with an IWP near $20 \mathrm{~g} \mathrm{~m}^{-2}$ are most important radiatively in both the observations and model.

In terms of assessing high clouds in models, our results suggest studies that use mean properties (i.e., mean IWP) as a metric for evaluating simulated ice clouds are misguided at least in terms of assessing TOA radiative effects. An emphasis on the mean IWP is not relevant to the TOA radiative balance for either the observation or model, given the skewed nature of the IWP distribution. The mean IWP tends to be more characteristic of an optically thick ice cloud, and not representative of the more commonly occurring ice clouds with smaller IWPs that seem to characterize the TOA net radiative effects. 
(a)

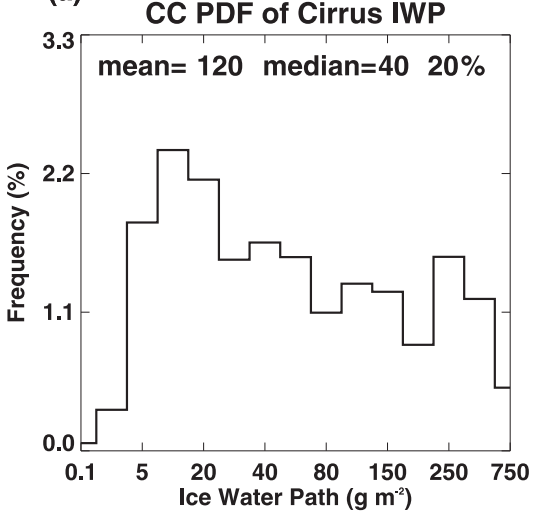

(d)

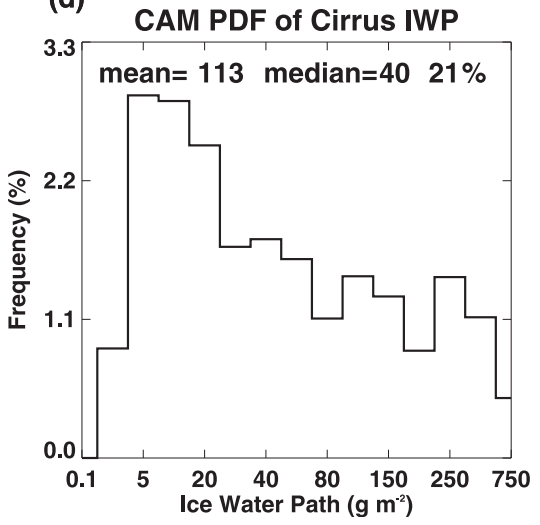

(b)

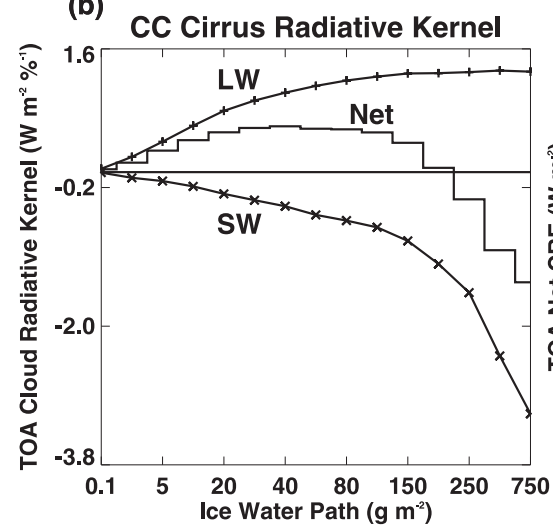

(e)

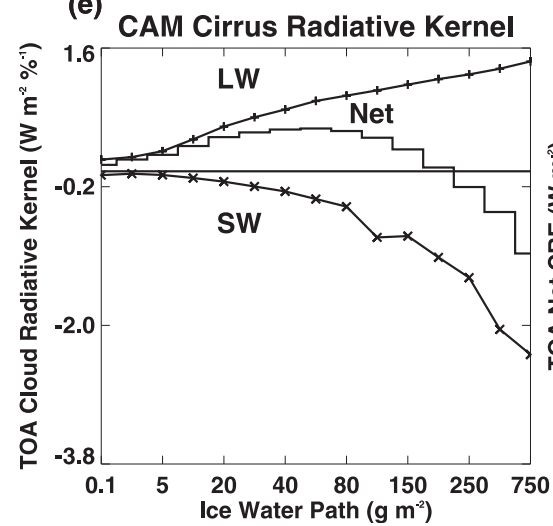

(c)

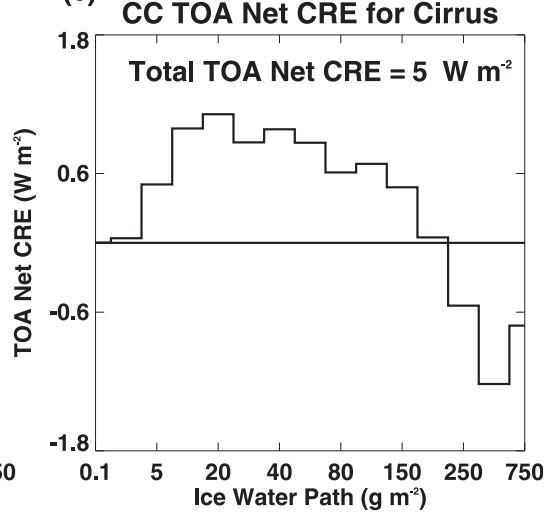

(f)

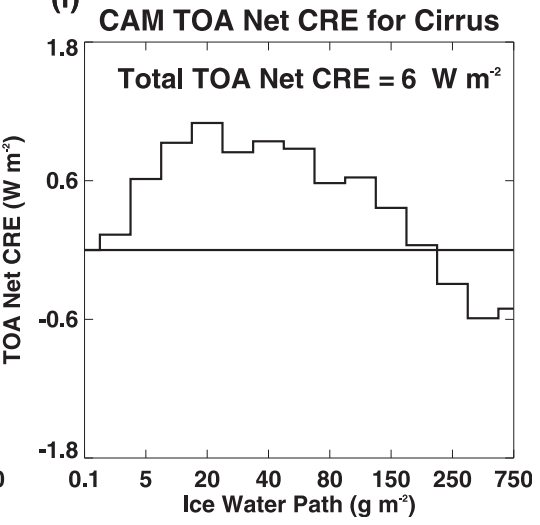

FIG. 11. Distribution of ice water path and cloud radiative effects for single-layer cirrus clouds (CTH $>9.5 \mathrm{~km}, \tau<23)$ in $($ a) $-(\mathrm{c}) C C$ observations and (d)-(f) CAM5. (a),(d) The corresponding PDFs of IWP, along with relevant statistics (mean and median IWP and relative frequency of single-layer cirrus). (b),(e) TOA longwave, shortwave, and net cloud radiative kernels as a function of IWP. (c),(f) The resulting TOA net cloud radiative effects (frequency $\times$ net cloud radiative kernel) and the summed net effect of all singlelayer cirrus.

On the implications for understanding simulated highcloud feedbacks, our results suggest that the radiative effects of present-day tropical ice clouds in CAM5 are being realistically portrayed. This accurate initial condition for cirrus lends some credibility to the positive LW feedback found in many GCMs that is associated with the PHAT hypothesis and rising tropical ice clouds. If the LW CRE of cirrus increased at the TOA (all else remaining the same), the LW curve in Fig. 11b would have a larger magnitude, and the crossover point for the Net CRE curve would shift toward larger IWPs. Hence, while cirrostratus exhibit a near neutral/slightly negative net CRE as shown in Fig. 10, there is the potential for cirrostratus clouds to contribute a warming effect in a warmer Earth.

\section{Summary}

In this paper, we present a comparison of clouds and their radiation effects from $C C$ observations and a
CAM5 simulation during two monsoon periods in Southeast Asia. In particular, we focus on evaluating the representation of ice clouds in the model. To accomplish this, we take advantage of the active remote sensors in the A-Train and their ability to observe a comprehensive range of optically thin to optically thick clouds and the vertically resolved cloud properties made possible by the $C C$ satellites.

Following Zelinka et al. (2012), we examine cloud fraction as a joint function of cloud properties $(\mathrm{CTH}$ and $\tau$ ). Cloud layers in the observations are identified using the radar-lidar mask in the 2B-GEOPROF-lidar CloudSat dataset, while the cloud layers in the model subcolumns are identified using the cloud fraction in CAM5. We would obtain similar clouds had we used the COSP simulator for $C C$ observations in CAM5. Overall, high-cloud types and optically thin cloud types are most prevalent in the CC observations and CAM5. The single-layer cloud fraction is close to $45 \%$ in both the observations and model, with differences appearing in 
the distribution of cloud types, mainly more cirrus and less stratocumulus in CAM5 compared to the $C C$ observations. Including all cloudy profiles (single and multiple cloud layers), the cloud fraction in CAM5 is $74 \%$, which is quite a bit lower than the overall $88 \%$ cloud fraction from the $C C$ observations. When considering the distribution of cloud types among all cloud layers, we find that CAM5 produces a greater fraction of optically thin high clouds compared to the observations.

The cloud radiative kernels derived in this study are based on populations of observed and simulated clouds, separately. This is different from the traditional cloud radiative kernels (Zelinka et al. 2012; Zhou et al. 2013), which are essentially based on synthetic cloud types. The benefit of these averaged cloud radiative kernels is that they reflect the actual populations of clouds that exist within the cloud-type bins, and are consistent with the cloud fraction histograms.

Our derived cloud radiative kernels depend on the retrieved and simulated cloud microphysical properties (water content and $r_{e}$ ). For the observations, the icecloud microphysics are obtained from the radar-lidar retrieval in the 2C-ICE CloudSat dataset, which is combined with a liquid-cloud retrieval below the melting level. The observed atmospheric quantities are obtained from the ECMWF-AUX CloudSat dataset. For the model, we include both in-cloud ice and snow in the ice-cloud microphysics, and we use the atmospheric variables in the model output. The same parameterizations are used to calculate the radiative properties from the observed and simulated microphysics. The same radiative transfer model is applied to all the observed cloudy profiles and cloudy model subcolumns to obtain the radiative fluxes and calculate the cloud radiative effect. The cloud radiative kernels are determined by calculating the average cloud radiative effect for a given cloud type and dividing by $100 \%$. This way, we can compare the sensitivity of the TOA fluxes to changes in cloud fraction in the observations and the model.

There are several important findings from this study. The radiative kernels demonstrate that the model and observations show a similar sensitivity of the TOA radiation to changes in cloud fraction for most cloud types with small and moderate optical depths, with a tendency for stronger cooling for low clouds in CAM5. When we account for diurnal cloud fraction differences between the model and observations by examining daytime and nighttime radiative effects separately, we find better agreement for optically thick clouds than originally suggested by the cloud radiative kernel. This suggests that it is the diurnal cycle of convection that contributes significantly to the CRE biases. Overall, the relatively good agreement in daytime CRE and nighttime CRE means that the clouds in the model are heating and cooling like $C C$-observed clouds.

Multiplying the cloud radiative kernels by the cloud fraction histograms gives the resulting CRE for singlelayer clouds. We find remarkable agreement in CRE between $C C$ and CAM5 for ice clouds. Both the model and observations show that optically thin cirrus are responsible for a warming effect on the order of $7 \mathrm{~W} \mathrm{~m}^{-2}$, while cirrostratus have a slightly negative contribution of $-2 \mathrm{~W} \mathrm{~m}^{-2}$. This agreement in CRE for ice clouds is due to relatively good agreement in both cloud fraction and cloud heating/cooling (cloud radiative kernel). However, there are small compensating differences. While the fraction of single-layer ice clouds is $24 \%$ in $C C$ and CAM5, the model produces slightly more cirrus and less cirrostratus compared to $C C$ (Fig. 5). Additionally, the CAM5 cirrus produce less heating and cirrostratus produce more cooling compared to $C C$ (Fig. 7). These small differences in ice-cloud fraction and cloud radiative kernel counteract each other, leading to the agreement in CRE (Fig. 10).

The main caveat of this study is that it focuses on a particular region and short time frame, specifically Southeast Asia $\left(5^{\circ} \mathrm{S}-25^{\circ} \mathrm{N}, 80^{\circ}-120^{\circ} \mathrm{E}\right)$ during the monsoon months of June-September 2007-08. However, it is reasonable to expect that these cloud-type results would be representative of cloud types in deep convective regions in the tropics. In this study, we have addressed the effects of differences in the observed and simulated microphysics on the radiation. In the future, we plan to examine the cloud microphysical properties individually, in more detail. The active remote sensors in the A-Train provide an excellent dataset for evaluating the water content and effective radius in models. This is an important next step, as the cloud microphysical properties could be a source of compensating errors, and these quantities play a role in processes relating to cloud lifetime.

The results in this paper have implications for our understanding of the role of ice clouds in the climate system and of model-predicted ice-cloud feedbacks. We find that the current representation of ice clouds in CAM5 is realistic in terms of radiative effects with relatively tenuous cirrus in the $20 \mathrm{~g} \mathrm{~m}^{-2}$ range contributing most to their TOA radiative effects. The agreement between the model and observations provides confidence to the predicted positive longwave feedback associated with rising high clouds under climate warming. Assuming that the frequency distribution of tropical ice clouds remains the same and the thermodynamics of the cirrus remains at constant temperature (the PHAT hypothesis) as the climate changes, we infer that this increasing LW forcing with warming (i.e., a positive feedback) will shift the 
crossover point between warming and cooling (Fig. 11b) to thicker ice clouds causing cirrostratus to become increasingly relevant to heating at the TOA.

Of the many feedbacks in the climate system that are reasonably understood, the ascent of tropical ice clouds is thought to be one of the most readily observed with the signal emerging from the natural noise of the climate system perhaps in the next decade (Chepfer et al. 2014; Marvel et al. 2015). It will be critical that measurement systems are suitable to document the emergence of this signal. As discussed in Berry and Mace (2014) and implied by these results, the ice clouds involved in this feedback occupy a particular portion of the IWP frequency distribution that require both a millimeter radar and an optical lidar to accurately characterize their properties and occurrence. Indeed, the fortuitous combination of the CloudSat W-band radar and the CALIPSO lidar enabled the present work and a future observing system with at least equivalent capabilities will be required to document what will be the first significant observable positive feedback in the present evolution of Earth's climate.

Acknowledgments. The A-Train data used in this study were acquired through the public CloudSat data archive at CIRA/CSU. The authors thank the anonymous reviewers for their thoughtful comments that greatly improved the manuscript. Support for this work was provided primarily by NASA Grant NNX13AQ34G and also by NASA Grants NNX10AM42G and NNX15AK17G.

\section{REFERENCES}

Ackerman, T. P., K-N. Liou, F. P. J. Valero, and L. Pfister, 1988: Heating rates in tropical anvils. J. Atmos. Sci., 45, 16061623, https://doi.org/10.1175/1520-0469(1988)045<1606: HRITA $>2.0 . \mathrm{CO} ; 2$

Andrews, T., J. M. Gregory, M. J. Webb, and K. E. Taylor, 2012: Forcing, feedbacks and climate sensitivity in CMIP5 coupled atmosphere-ocean climate models. Geophys. Res. Lett., 39, L09712, https://doi.org/10.1029/2012gl051607.

Battaglia, A., M. O. Ajewole, and C. Simmer, 2007: Evaluation of radar multiple scattering effects in CloudSat configuration. Atmos. Chem. Phys., 7, 1719-1730, https://doi.org/10.5194/ acp-7-1719-2007.

Berry, E., and G. G. Mace, 2014: Cloud properties and radiative effects of the Asian summer monsoon derived from A-Train data. J. Geophys. Res Atmos., 119, 9492-9508, https://doi.org/ 10.1002/2014jd021458.

Bodas-Salcedo, A., and Coauthors, 2011: COSP: Satellite simulation software for model assessment. Bull. Amer. Meteor. Soc., 92, 1023-1043, https://doi.org/10.1175/2011BAMS2856.1.

Bony, S., and J.-L. Dufresne, 2005: Marine boundary layer clouds at the heart of tropical cloud feedback uncertainties in climate models. Geophys. Res. Lett., 32, L20806, https://oi.org/ 10.1029/2005GL023851.
Boucher, O., and Coauthors, 2013: Clouds and aerosols. Climate Change 2013: The Physical Science Basis, T. F. Stocker et al., Eds., Cambridge University Press, 571-657.

Caldwell, P. M., M. D. Zelinka, K. E. Taylor, and K. Marvel, 2016: Quantifying the sources of intermodel spread in equilibrium climate sensitivity. J. Climate, 29, 513-524, https://doi.org/ 10.1175/JCLI-D-15-0352.1.

Ceppi, P., D. T. McCoy, and D. L. Hartmann, 2016: Observational evidence for a negative shortwave cloud feedback in middle to high latitudes. Geophys. Res. Lett., 43, 1331-1339, https:// doi.org/10.1002/2015GL067499.

Cesana, G., and D. E. Waliser, 2016: Characterizing and understanding systematic biases in the vertical structure of clouds in CMIP5/CFMIP2 models. Geophys. Res. Lett., 43, 10 538-10 546, https://doi.org/10.1002/2016GL070515.

Chepfer, H., V. Noel, D. Winker, and M. Chiriaco, 2014: Where and when will we observe cloud changes due to climate warming? Geophys. Res. Lett., 41, 8387-8395, https://doi.org/ 10.1002/2014GL061792.

Collins, W. D., 2001: Parameterization of generalized cloud overlap for radiative calculations in general circulation models. J. Atmos. Sci., 58, 3224-3242, https://doi.org/10.1175/15200469(2001)058<3224:POGCOF $>2.0 . C O ; 2$.

Das, S. K., R. B. Golhait, and K. N. Uma, 2017: Cloud vertical properties over the Northern Hemisphere monsoon regions from CloudSat-CALIPSO measurements. Atmos. Res., 183, 73-83, https://doi.org/10.1016/j.atmosres.2016.08.011.

Delanoë, J., and R. J. Hogan, 2010: Combined CloudSatCALIPSO-MODIS retrievals of the properties of ice clouds. J. Geophys. Res., 115, D00H29, https://doi.org/10.1029/ 2009JD012346.

Deng, M., G. G. Mace, Z. Wang, R. P. Lawson, 2013: Evaluation of several A-Train ice cloud retrieval products with in situ measurements collected during the SPARTICUS campaign. J. Appl. Meteor. Climatol., 52, 1014-1030, https://doi.org/ 10.1175/JAMC-D-12-054.1.

,,--- , and E. Berry, 2015: CloudSat 2C-ICE product update with a new $\mathrm{Z}_{\mathrm{e}}$ parameterization in lidar-only region. J. Geophys. Res. Atmos., 120, 12 198-12 208, https://doi.org/ 10.1002/2015jd023600.

Dolinar, E. K., X. Dong, B. Xi, J. H. Jiang, and H. Su, 2015: Evaluation of CMIP5 simulated clouds and TOA radiation budgets using NASA satellite observations. Climate Dyn., 44, 2229-2247, https://doi.org/10.1007/s00382-014-2158-9.

Dufresne, J.-L., and S. Bony, 2008: An assessment of the primary sources of spread of global warming estimates from coupled atmosphere-ocean models. J. Climate, 21, 5135-5144, https:// doi.org/10.1175/2008JCLI2239.1.

Fu, Q., 1996: An accurate parameterization of the solar radiative properties of cirrus clouds for climate models. J. Climate, 9 , 2058-2082, https://doi.org/10.1175/1520-0442(1996)009<2058: AAPOTS $>2.0 . \mathrm{CO} ; 2$.

- P. Yang, and W. B. Sun, 1998: An accurate parameterization of the infrared radiative properties of cirrus clouds for climate models. J. Climate, 11, 2223-2237, https://doi.org/10.1175/ 1520-0442(1998)011<2223:AAPOTI >2.0.CO;2.

Gettelman, A., and S. C. Sherwood, 2016: Processes responsible for cloud feedback. Curr. Climate Change Rep., 2, 179-189, https://doi.org/10.1007/s40641-016-0052-8.

, and Coauthors, 2010: Global simulations of ice nucleation and ice supersaturation with an improved cloud scheme in the Community Atmosphere Model. J. Geophys. Res., 115, D18216, https://doi.org/10.1029/2009JD013797. 
Haynes, J. M., T. S. L'Ecuyer, G. L. Stephens, S. D. Miller, C. Mitrescu, N. B. Wood, and S. Tanelli, 2009: Rainfall retrieval over the ocean with spaceborne W-band radar. J. Geophys. Res., 114, D00A22, https://doi.org/10.1029/2008JD009973.

Henderson, D. S., T. L'Ecuyer, G. Stephens, P. Partain, and M. Sekiguchi, 2013: A multisensor perspective on the radiative impacts of clouds and aerosols. J. Appl. Meteor. Climatol., 52, 853-871, https://doi.org/10.1175/JAMC-D-12-025.1.

Hong, Y., and G. Liu, 2015: The characteristics of ice cloud properties derived from CloudSat and CALIPSO measurements. J. Climate, 28, 3880-3901, https://doi.org/10.1175/JCLI-D-1400666.1.

— clouds based on CloudSat and CALIPSO measurements. J. Climate, 29, 7651-7674, https://doi.org/10.1175/JCLI-D-150799.1.

Iacono, M. J., J. S. Delamere, E. J. Mlawer, M. W. Shephard, S. A. Clough, and W. D. Collins, 2008: Radiative forcing by longlived greenhouse gases: Calculations with the AER radiative transfer models. J. Geophys. Res., 113, D13103, https://doi.org/ 10.1029/2008JD009944.

Jakob, C., and S. A. Klein, 1999: The role of vertically varying cloud fraction in the parametrization of microphysical processes in the ECMWF model. Quart. J. Roy. Meteor. Soc., 125, 941-965, https://doi.org/10.1002/qj.49712555510.

Jiang, J. H., and Coauthors, 2012: Evaluation of cloud and water vapor simulations in CMIP5 climate models using NASA "ATrain" satellite observations. J. Geophys. Res., 117, D14105, https://doi.org/10.1029/2011JD017237.

Kato, S., G. L. Smith, and H. W. Barker, 2001: Gamma-weighted discrete ordinate two-stream approximation for computation of domain-averaged solar irradiance. J. Atmos. Sci., 58, 3797-3803, https://doi.org/10.1175/1520-0469(2001)058<3797: GWDOTS $>2.0 . \mathrm{CO} ; 2$.

—, N. G. Loeb, F. G. Rose, D. R. Doelling, D. A. Rutan, T. E. Caldwell, L. Yu, and R. A. Weller, 2013: Surface irradiances consistent with CERES-derived top-of-atmosphere shortwave and longwave irradiances. J. Climate, 26, 2719-2740, https:// doi.org/10.1175/JCLI-D-12-00436.1.

Kiehl, J., J. Hack, G. B. Bonan, B. A. Boville, D. L. Williamson, and P. J. Rasch, 1998: The National Center for Atmospheric Research Community Climate Model: CCM3. J. Climate, 11, 1131-1149, https://doi.org/10.1175/1520-0442(1998)011<1131: TNCFAR $>2.0 . \mathrm{CO} ; 2$.

Klein, S. A., Y. Zhang, M. D. Zelinka, R. Pincus, J. Boyle, and P. J. Gleckler, 2013: Are climate model simulations of clouds improving? An evaluation using the ISCCP simulator. J. Geophys. Res. Atmos., 118, 1329-1342, https://doi.org/ 10.1002/jgrd.50141.

Lauer, A., and K. Hamilton, 2013: Simulating clouds with global climate models: A comparison of CMIP5 results with CMIP3 and satellite data. J. Climate, 26, 3823-3845, https://doi.org/ 10.1175/JCLI-D-12-00451.1.

L'Ecuyer, T., and J. Jiang, 2010: Touring the atmosphere aboard the A-Train. Phys. Today, 63, 36-41, https://doi.org/10.1063/ 1.3463626

Li, J.-L. F., and Coauthors, 2012: An observationally based evaluation of cloud ice water in CMIP3 and CMIP5 GCMs and contemporary reanalyses using contemporary satellite data. J. Geophys. Res., 117, D16105, https://doi.org/10.1029/ 2012jd017640.

—, W.-L. Lee, D. E. Waliser, J. P. Stachnik, E. Fetzer, S. Wong, and Q. Yue, 2014: Characterizing tropical Pacific water vapor and radiative biases in CMIP5 GCMs: Observation-based analyses and a snow and radiation interaction sensitivity experiment. J. Geophys. Res. Atmos., 119, 10 981-10 995, https:// doi.org/10.1002/2014JD021924.

Mace, G. G., 2010: Cloud properties and radiative forcing over the maritime storm tracks of the North Atlantic and Southern Ocean as derived from A-Train. J. Geophys. Res., 115, D10201, https://doi.org/10.1029/2009JD012517.

_ - and F. J. Wrenn, 2013: Evaluation of hydrometeor layers in the east and west Pacific within ISCCP cloud-top pressure-optical depth bins using merged CloudSat and CALIPSO data. J. Climate, 26, 9429-9444, https://doi.org/10.1175/JCLI-D-12-00207.1.

— , and Q. Zhang, 2014: The CloudSat radar-lidar geometrical profile product (RL-GeoProf): Updates, improvements, and selected results. J. Geophys. Res. Atmos., 119, 9441-9462, https://doi.org/10.1002/2013JD021374.

— , and E. Berry, 2017: Using active remote sensing to evaluate cloud-climate feedbacks: A review and a look to the future Curr. Climate Change Rep., 3, 185-192, https://doi.org/10.1007/ s40641-017-0067-9.

_ , R. Marchand, Q. Zhang, and G. Stephens, 2007: Global hydrometeor occurrence as observed by CloudSat: Initial observations from summer 2006. Geophys. Res. Lett., 34, L09808, https://doi.org/10.1029/2006GL029017.

_, Q. Zhang, M. Vaughn, R. Marchand, G. Stephens, C. Trepte, and D. Winker, 2009: A description of hydrometeor layer occurrence statistics derived from the first year of merged Cloudsat and CALIPSO data. J. Geophys. Res., 114, D00A26, https://doi.org/10.1029/2007JD009755.

Marvel, K., M. Zelinka, S. A. Klein, C. Bonfils, P. Caldwell, C. Doutriaux, B. D. Sandter, and K. E. Taylor, 2015: External influence on modeled and observed cloud trends. J. Climate, 28, 4820-4900, https://doi.org/10.1175/JCLI-D-14-00734.1.

Matrosov, S. Y., A. Battaglia, and P. Rodriguez, 2008: Effects of multiple scattering on attenuation-based retrievals of stratiform rain from CloudSat. J. Atmos. Oceanic Technol., 25, 2199-2208, https://doi.org/10.1175/2008JTECHA1095.1.

Mlawer, E. J., S. J. Taubman, P. D. Brown, M. J. Iacono, and S. A. Clough, 1997: Radiative transfer for inhomogeneous atmospheres: RRTM, a validated correlated-k model for the longwave.J. Geophys. Res., 102, 16 663-16 682, https://doi.org/ 10.1029/97JD00237.

Morrison, H., and A. Gettelman, 2008: A new two-moment bulk stratiform cloud microphysics scheme in the Community Atmosphere Model, version 3 (CAM3). Part I: Description and numerical tests. J. Climate, 21, 3642-3659, https://doi.org/ 10.1175/2008JCLI2105.1.

Nam, C., S. Bony, J.-L. Dufresne, and H. Chepfer, 2012: The 'too few, too bright' tropical low-cloud problem in CMIP5 models. Geophys. Res. Lett., 39, L21801, https://doi.org/10.1029/2012gl053421.

Neale, R. B., and Coauthors, 2010: Description of the NCAR Community Atmosphere Model (CAM 5.0). NCAR Tech. Note NCAR/TN-486+STR, 268 pp., www.cesm.ucar.edu/ models/cesm1.1/cam/docs/description/cam5_desc.pdf.

Norris, J. R., R. J. Allen, A. T. Evan, M. D. Zelinka, C. W. O’Dell, and S. A. Klein, 2016: Evidence for climate change in the satellite cloud record. Nature, 536, 72-75, https://doi.org/ 10.1038/nature18273.

Park, S., and C. S. Bretherton, 2009: The University of Washington shallow convection and moist turbulence schemes and their impact on climate simulations with the Community Atmosphere Model. J. Climate, 22, 3449-3469, https://doi.org/ 10.1175/2008JCLI2557.1. 
Partain, P., 2007: CloudSat ECMWF-AUX auxiliary data process description and interface control document. Cooperative Institute for Research in the Atmosphere, Colorado State University, $11 \mathrm{pp}$.

Rossow, W. B., and R. A. Schiffer, 1999: Advances in understanding clouds from ISCCP. Bull. Amer. Meteor. Soc., 80, 2261-2288, https://doi.org/10.1175/1520-0477(1999)080<2261: AIUCFI $>2.0 . C O ; 2$.

Sherwood, S. C., S. Bony, and J.-L. Dufresne, 2014: Spread in model climate sensitivity traced to atmospheric convective mixing. Nature, 505, 37-42, https://doi.org/10.1038/nature12829.

Slingo, J. M., 1989: A GCM parameterization for the shortwave radiative properties of water clouds. J. Atmos. Sci., 46, 1419-1427, https:// doi.org/10.1175/1520-0469(1989)046<1419:AGPFTS >2.0.CO;2.

Soden, B. J., and I. M. Held, 2006: An assessment of climate feedbacks in coupled ocean-atmosphere models. J. Climate, 19, 3354-3360, https://doi.org/10.1175/JCLI3799.1.

_ , and G. A. Vecchi, 2011: The vertical distribution of cloud feedback in coupled ocean-atmosphere models. Geophys. Res. Lett., 38, L12704, https://doi.org/10.1029/2011GL047632.

- A. M. Broccoli, and R. S. Hemler, 2004: On the use of cloud forcing to estimate cloud feedback. J. Climate, 17, 3661-3665, https://doi.org/10.1175/1520-0442(2004)017<3661:OTUOCF $>$ 2.0.CO;2.

- I. M. Held, R. Colman, K. M. Shell, J. T. Kiehl, and C. A. Shields, 2008: Quantifying climate feedbacks using radiative kernels. J. Climate, 21, 3504-3520, https://doi.org/10.1175/ 2007JCLI2110.1.

Stephens, G. L., 2005: Cloud feedback in the climate system: A critical review. J. Climate, 18, 237-273, https://doi.org/10.1175/ JCLI-3243.1.

- , D. Winker, J. Pelon, C. Trepte, D. Vane, C. Yuhas, T. L'Ecuyer, and M. Lebsock, 2018: CloudSat and CALIPSO within the A-Train: Ten years of actively observing the Earth system. Bull. Amer. Meteor. Soc., 99, 569-581, https://doi.org/ 10.1175/bams-d-16-0324.1.

Stevens, B., and S. Bony, 2013: What are climate models missing? Science, 340, 1053-1054, https://doi.org/10.1126/science.1237554.

Su, H., and Coauthors, 2013: Diagnosis of regime-dependent cloud simulation errors in CMIP5 models using "A-Train" satellite observations and reanalysis data. J. Geophys. Res. Atmos., 118, 2762-2780, https://doi.org/10.1029/2012JD018575.

Tanelli, S., S. L. Durden, K. S. Pak, D. G. Reinke, P. Partain, J. M. Haynes, and R. T. Marchand, 2008: CloudSat's cloud profiling radar after two years in orbit: Performance, calibration, and processing. IEEE Trans. Geosci. Remote Sens., 46, 3560-3573, https://doi.org/10.1109/TGRS.2008.2002030.

Taylor, K. E., R. J. Stouffer, and G. A. Meehl, 2012: An overview of CMIP5 and the experiment design. Bull. Amer. Meteor. Soc., 93, https://doi.org/10.1175/BAMS-D-11-00094.1.

Toon, O. B., C. P. McKay, T. P. Ackerman, and K. Santhanam, 1989: Rapid calculation of radiative heating rates and photodissociation rates in inhomogeneous multiple scattering at- mospheres. J. Geophys. Res., 94, 16287-16301, https://doi.org/ 10.1029/JD094iD13p16287.

Tsushima, Y., M. A. Ringer, M. J. Webb, and K. D. Williams, 2013: Quantitative evaluation of the seasonal variations in climate model cloud regimes. Climate Dyn., 41, 2679-2696, https:// doi.org/10.1007/s00382-012-1609-4.

Vial, J., J.-L. Dufresne, and S. Bony, 2013: On the interpretation of inter-model spread in CMIP5 climate sensitivity estimates. Climate Dyn., 41, 3339-3362, https://doi.org/10.1007/s00382013-1725-9.

Waliser, D. E., and Coauthors, 2009: Cloud ice: A climate model challenge with signs and expectations of progress. J. Geophys. Res., 114, D00A21, https://doi.org/10.1029/2008JD010015.

— J.-L. F. Li, T. S. L'Ecuyer, and W.-T. Chen, 2011: The impact of precipitating ice and snow on the radiation balance in global climate models. Geophys. Res. Lett., 38, L06802, https:// doi.org/10.1029/2010GL046478.

Wang, H., and W. Su, 2013: Evaluating and understanding top of the atmosphere cloud radiative effects in Intergovernmental Panel on Climate Change (IPCC) Fifth Assessment Report (AR5) Coupled Model Intercomparison Project Phase 5 (CMIP5) models using satellite observations. J. Geophys. Res Atmos., 118, 683-699, https://doi.org/10.1029/2012JD018619.

Winker, D., and Coauthors, 2010: The CALIPSO mission. Bull. Amer. Meteor. Soc.91, 1211-1229, https://doi.org/10.1175/ 2010BAMS3009.1.

Yue, Q., B. H. Kahn, E. J. Fetzer, M. Schreier, and S. Wong, 2016: Observation-based longwave cloud radiative kernels derived from the A-Train. J. Climate, 29, 2023-2040, https://doi.org/ 10.1175/JCLI-D-15-0257.1.

Zelinka, M. D., and D. L. Hartmann, 2010: Why is longwave cloud feedback positive? J. Geophys. Res., 115, D16117, https:// doi.org/10.1029/2010JD013817.

—, S. A. Klein, and D. L. Hartmann, 2012: Computing and partitioning cloud feedbacks using cloud property histograms. Part I: Cloud radiative kernels. J. Climate, 25, 3715-3735, https://doi.org/10.1175/JCLI-D-11-00248.1.

,,- K. E. Taylor, T. Andrews, M. J. Webb, J. M. Gregory, and P. M. Forster, 2013: Contributions of different cloud types to feedbacks and rapid adjustments in CMIP5. J. Climate, 26, 5007-5027, https://doi.org/10.1175/JCLI-D-12-00555.1.

Zhang, G. J., and N. A. McFarlane, 1995: Sensitivity of climate simulations to the parameterization of cumulus convection in the Canadian Climate Centre general circulation model. Atmos.-Ocean, 33, 407-446, https://doi.org/10.1080/ 07055900.1995 .9649539$.

Zhou, C., M. D. Zelinka, A. E. Dessler, and P. Yang, 2013: An analysis of the short-term cloud feedback using MODIS data. J. Climate, 26, 4803-4815, https://doi.org/10.1175/JCLI-D-1200547.1.

, A. E. Dessler, M. D. Zelinka, P. Yang, and T. Wang, 2014: Cirrus feedback on interannual climate fluctuations. Geophys. Res. Lett., 41, 9166-9173, https://doi.org/10.1002/2014GL062095. 